\title{
Measuring the relative importance of different agricultural \\ inputs to global and regional crop yield growth since 1975
}

\section{[version 1; peer review: 2 approved with reservations]}

\section{Erik Nelson (iD1, Clare Bates Congdon²}

${ }^{1}$ Department of Economics, Bowdoin College, Brunswick, USA

${ }^{2}$ Department of Computer Science, Bowdoin College, Brunswick, USA

V1 First published: $29 \operatorname{Dec} 2016, \mathbf{5 : 2 9 3 0}$

https://doi.org/10.12688/f1000research.10419.1

Latest published: 29 Dec 2016, 5:2930

https://doi.org/10.12688/f1000research.10419.1

\section{Abstract}

Background: We identify the agricultural inputs that drove the growth in global and regional crop yields from 1975 to the mid-2000s. Methods: We compare and contrast the inputs that drove yield change as identified by econometrically estimated yield functions and decision trees that use yield change as the class attribute. Results: We find that improvements in agricultural science and management, increased fertilizer use, and changes in crop mix around the world explained most of the gain in global crop yields, although the yield impacts of input use varied across the latitudinal gradient. Climate change over this time period caused yields to be only slightly lower than they would have been otherwise. In some cases, cropland extensification had as much of a negative impact on global and regional yields as climate change. Conclusions: To maintain the momentum in yield growth across the globe 1) the transfer of agricultural chemicals and investment in agricultural science and management in the tropics must increase rapidly and 2) international trade in agricultural products must expand significantly.

Keywords

climate change, agricultural yields, cropland extensification, econometrics, decision trees, international trade

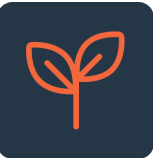

This article is included in the Agriculture, Food and Nutrition gateway.

\section{Open Peer Review \\ Approval Status? ? 2 \\ version 1

$\begin{array}{cc}? & ? \\ \text { view } & \text { view }\end{array}$ \\ 1. Timothy $\mathbf{S}$ Thomas, International Food Policy Research Institute (IFPRI), Washington, USA \\ 2. Nathaniel D Mueller, Harvard University, Cambridge, USA}

Any reports and responses or comments on the article can be found at the end of the article. 
This article is included in the Machine learning:

life sciences collection.

Corresponding author: Erik Nelson (enelson2@bowdoin.edu)

Competing interests: No competing interests were disclosed.

Grant information: The author(s) declared that no grants were involved in supporting this work.

Copyright: @ 2016 Nelson E and Congdon CB. This is an open access article distributed under the terms of the Creative Commons Attribution License, which permits unrestricted use, distribution, and reproduction in any medium, provided the original work is properly cited. Data associated with the article are available under the terms of the Creative Commons Zero "No rights reserved" data waiver (CCO 1.0 Public domain dedication).

How to cite this article: Nelson E and Congdon CB. Measuring the relative importance of different agricultural inputs to global and regional crop yield growth since 1975 [version 1; peer review: 2 approved with reservations] F1000Research 2016, 5:2930 https://doi.org/10.12688/f1000research.10419.1

First published: 29 Dec 2016, 5:2930 https://doi.org/10.12688/f1000research.10419.1 


\section{Introduction}

A consensus has emerged that recent climate change has had a negative effect on crop yields around the world (e.g., 1-4). Accelerating climate change is likely to put even more downward pressure on agricultural productivity around the world in coming years. Further, demand for food will grow quickly as the world races to a population of $\sim 12$ billion by $2100^{5}$. Therefore, the vital question is: How can the world's farmers increase crop productivity, as necessitated by global population growth, despite the expected drag on yields caused by climate change, while leaving the socially desirable amount of forest, grasslands, and other seminatural land cover around the world? ${ }^{6}$

Before suggesting a way forward on this issue, we first have to determine what agricultural inputs are most important to yield growth around the world. Here we use global yield and agricultural input data from 1975 to the mid-2000s to determine what agricultural production inputs were most responsible for the growth in global and regional yields during this time period. The inputs we consider include growing season weather, crop choice, investment in irrigation capability, land, and machinery, agricultural science and management, fertilizer use, cropped footprint ${ }^{7}$, and cropped soil quality. We find that improvements in agricultural science and management (e.g., technology and chemical use), increased fertilizer use, and changes in crop mix around the world explained most of the gain in global crop yields from 1975 to the mid-2000s. Improvements in agricultural science and management were particularly important drivers of yield growth in the temperate region and changes in crop mix and increased fertilizer use were particularly important drivers of yield growth in the tropics. Further, the deleterious impacts of climate change on yield were small compared to the yield-augmenting factors noted above. Finally, cropland extensification over the last 40 years has dragged average global yields down as well, sometimes as much as climate change has.

\section{A}

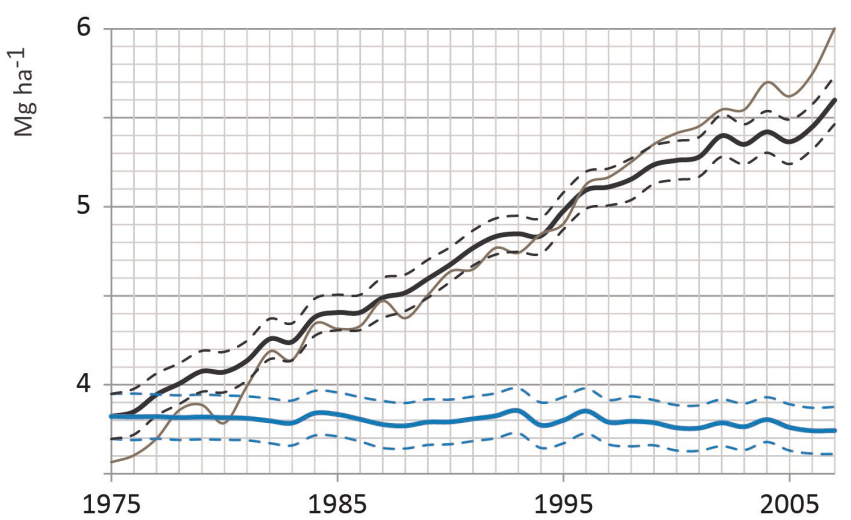

Our results indicate that 1) transferring better agricultural science and management and other inputs to the tropics, 2 ) encouraging countries to exclusively concentrate on growing the crops most suited to their soil-climate conditions (and trading for the rest of the crops their consumers want), and 3) focusing on increasing the productivity of existing cropland in lieu of concentrating on cropland extensification will be the most effective ways to ameliorate climate change's expected drag on global yields.

\section{Results}

We used two analytical methods to measure relative importance of agricultural inputs to the growth in global and regional crop yields between 1975 and the mid-2000s.

\section{First analytical method: econometrically estimated yield} functions

First, we estimated country-level yield functions with a fixedeffects econometric model using a 1975 to the mid-2000s global panel dataset (Supplementary Table 1 and Supplementary Table 2; Dataset 1 and Dataset $2^{8,9}$ ). We estimated country-level yield functions using both $\mathrm{Mg} \mathrm{ha}^{-1}$ and $\mathrm{M}$ kcals ha ${ }^{-1}$ yield metrics: $\mathrm{Mg}$ or M kcal production across all crops in a country in year $t$ divided by hectares of cropland in the country in year $t$. Second, we used the estimated yield functions and the panel data to obtain annual expected country-level yields, both in Mg ha ${ }^{-1}$ and M kcals ha ${ }^{-1}$, for the 1975 to the mid-2000s time period. Third, we generated global and regional expected crop yields in year $t$ by taking the weighted average of expected country-level yields in year $t$ using country-level cropped hectarage as weights. This process generated three expected "all-crop" yield curves, one for the globe, one for the temperate region, and one for the tropics region (see Figure 1 for the global $\mathrm{Mg} \mathrm{ha}^{-1}$ and $\mathrm{M}$ kcals ha ${ }^{-1}$ expected yield functions).

Figure 1. Expected global yield given 1975-2007 spatiotemporal data (black lines where dashed lines indicate $+/-$ one standard deviation) and numeraire counterfactual global yield (blue line where the dashed lines indicate $+/-$ one standard deviation). The counterfactual global yield curves were constructed by holding all country-level agricultural inputs at 1975 levels except growing season weather. These graphs are based on "long" model results (based on the dataset with 1975 to 2007 data). Expected global yield grew $46.5 \%$ when measured in $\mathrm{Mg} \mathrm{ha}^{-1}(\mathbf{A})$ and 58.8\% when measured in $\mathrm{M} \mathrm{kcals} \mathrm{ha-1}^{-1}(\mathbf{B})$ between 1975 and 2007. Under the numeraire counterfactual global yield fell 2.1\% when measured in $\mathrm{Mg} \mathrm{ha}^{-1}$ (A) and 2.5\% when measured in $\mathrm{M} \mathrm{kcals} \mathrm{ha-1}^{-1}$ (B) between 1975 and 2007 . The light gray line indicates observed global yields. 
To estimate the overall contribution of an agriculture production input or a group of inputs on 1975 to mid-2000s global or regional crop yield trends, we again found the expected global or region yield curve (as explained above) while holding the input or inputs in question fixed at observed 1975 levels (all other variables took on observed values). For example, to measure the impact of the change in cropped land soil quality on yield trends, the "soil quality" counterfactual yield curves were estimated with the quality of cropped land soil around the world remaining fixed at 1975 levels while all other inputs varied as observed. Then by integrating over the gap formed between the expected global or regional yield curve and the counterfactual global or regional yield curve we have measured the relative contribution of that input or group of inputs to 1975 to mid-2000s growth in global or regional yields, all else equal. The larger a counterfactual's integral (in absolute terms), the greater the impact that the input or group of inputs in question had on global or regional yield trends from 1975 to the mid-2000s. A positive (negative) integral means that the 1975 to mid-2000s changes in the input in question had, on net, a positive (negative) impact on average global or regional yield.

When discussing results below, we normalize the size of a counterfactual's integral by measuring its size relative to the size of the integral formed by the numeraire counterfactual. In a numeraire counterfactual all inputs are held at 1975 levels, except growing season weather over each country's crop production area, which varied as observed (the numeraire counterfactuals always form the largest integrals). We refer to a numeraire counterfactual's integral as the 'Mg gap' or the 'kcals gap' (Figure 2). For example, the mean global "crop mix" counterfactual has an integral of 9.11 over the 1975 to 2007 period when yield is measured in $\mathrm{Mg} \mathrm{ha}^{-1}$. The mean global "numeraire $\mathrm{Mg}$ " counterfactual produces an integral of 30.53. Thus, the mean global "crop mix" counterfactual makes up or explains $9.11 / 30.53=29.83 \%$ of the 1975 to 2007 global $\mathrm{Mg}$ gap. The larger the percentage, positive or negative, the more important the counterfactual's input or group of inputs was to determining the 1975 to mid-2000s global or regional yield trend.

\section{Second analytical method: decision trees based on yield change}

We also used decision tree algorithms to obtain a "second opinion" on which agricultural inputs were most important in explaining the growth in global and regional crop yields between 1975 and the mid-2000s. A decision tree segregates a process' outcomes (in our case, annual changes in observed country-level yields) based on the attributes of a process (in our case, annual changes in each country's input levels). A tree can be interpreted as the rules that map attributes of a process to the outcome of the process. In our case we find rules - ranges in annual changes in input levels - that predicted annual changes in country-level yields best (Supplementary Figure 1-Supplementary Figure 12; Dataset $3^{10}$ ). When using econometric techniques to build a yield function, we made several assumptions regarding the variable-generating process. In the decision tree analysis, a machine learning algorithm, we identified key features of the data without committing to statistical assumptions.

\section{The two panel datasets used in our analysis}

For each analytical method we discuss two sets of results. In one case, we derive results for the time period 1975 to 2007. However, this set of results does not include fertilizer as a production input. In the other case we derive results for the time period 1975 to 2002 . This set of results does include fertilizer use as an explanatory variable. The source of much of our agriculture data changed their fertilizer collection methods beginning in $2003^{11}$. Harmonizing the two fertilizer databases was not practical. Below we will refer to results derived from the 1975 to 2002 dataset as the "wide" results and results derived from the 1975 to 2007 dataset as the "long" results.
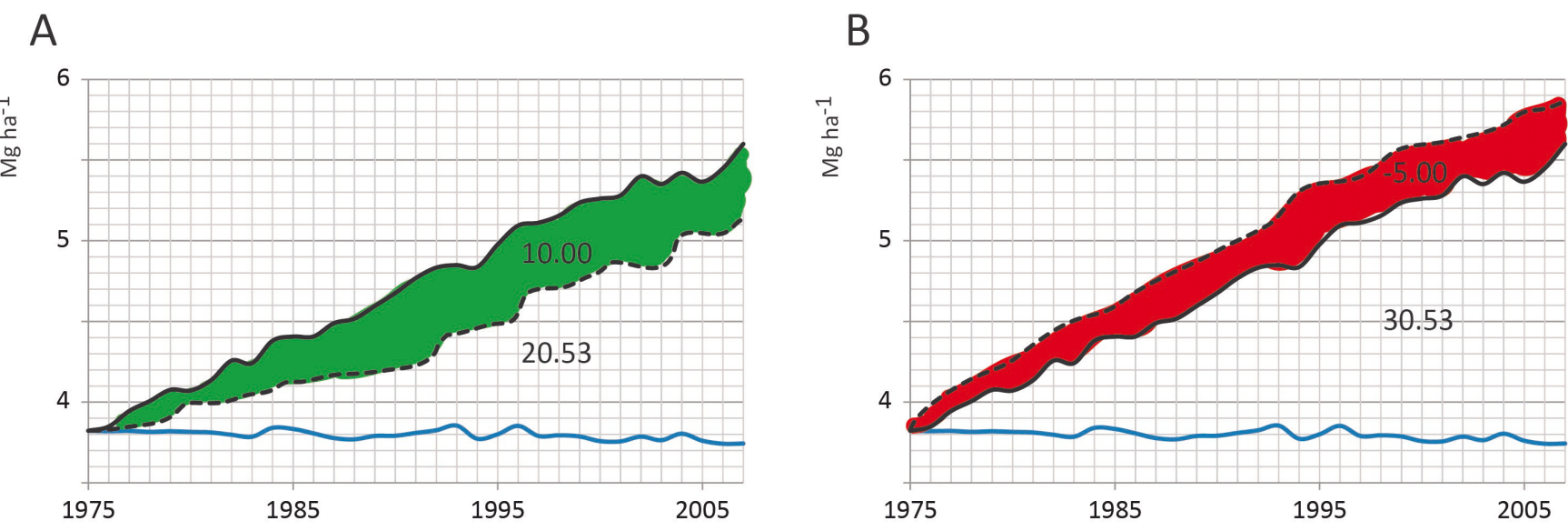

Figure 2. Measuring the impact of an agricultural input on 1975 to mid 2000 s global or regional yields. In (A) an estimated global or regional counterfactual yield curve (one or more inputs are held fixed at 1975 levels in each country), measured in Mg, is given by the dotted black line. Assume the integral of the area between the expected global or regional yield curve (the solid black line) and the estimated counterfactual global or region yield curve is 10.00. Further, assume the integral of the area between the expected global or regional yield curve (the solid black line) and the numeraire counterfactual yield curve (the solid blue line) is 30.53. Then the counterfactual explains $10 / 30.53$ or $33 \%$ of the "global Mg gap." In (B) the estimated global or regional counterfactual explains $-5 / 30.53$ or $-16 \%$ of the "global Mg gap." 


\section{Dataset 1. "Wide" datase}

http://dx.doi.org/10.5256/f1000research.10419.d146338

1) ID: UNFAO Country Code; 2) Year; 3) Tropical: a 1 indicates that that country is a tropical country and a 0 indicates that the country is a temperate country; 4) tons/ha: a country's crop yield in year t in metric tons/ha (I summed all tons of crops produced in a country and divided by total cropped hectares in a country); 5) million kcals/ha: a country's crop yield in year t in millions of kcals/ha (I summed all kcals of crops produced in a country and divided by total cropped hectares in a country); 6) soilscore: The composite soil quality score of the land that was cropped in year t in country $\mathrm{k}$ (on a 1 to 5 scale with lower numbers indicating better soil); 7) ha: total cropped hectares in year $t$ in country $k ; 8)$ rice: percentage of cropped area in rice in year $t$ in country $k ; 9$ ) wheat: percentage of cropped area in wheat in year t in country $k ; 10)$ sugar: percentage of cropped area in sugarcane in year t in country $k ; 11$ ) grains: percentage of cropped area in coarse grains in year $t$ in country $k$; 12) oil: percentage of cropped area in oil crops in year $t$ in country $k$ 13) fruits: percentage of cropped area in fruits in year t in country $k$; 14) roots: percentage of cropped area in roots and tubers in year $t$ in country k; 15) other: percentage of cropped area in all other crops in year t in country k; 16) davg: The composite average daytime temperature over cropped lands during the growing season year t in country $\mathrm{k}$ (Celsius); 17) navg: The composite average nighttime temperature over cropped lands during the growing season year $t$ in country k (Celsius); 18) pavg: The total rainfall over cropped lands during the growing season year t in country $\mathrm{k}(\mathrm{mm})$; 19$)$ irr: Fraction of cropped lands that are equipped for irrigation in year $t$ in country k; 20) land: total money invested in agricultural land development divided by cropped hectares in year t in country k (2005 constant US \$(ha); 21) eqp: total money invested in agricultural equipment divided by cropped hectares in year $\mathrm{t}$ in country k (2005 constant US \$/ha); 22) fert: kilograms of fertilizer used in the country divicde by cropped hectares in year $t$ in country $k$

\section{Dataset 2. "Long" dataset}

http://dx.doi.org/10.5256/f1000research.10419.d146339

1) ID: UNFAO Country Code; 2) Year; 3) Tropical: a 1 indicates that that country is a tropical country and a 0 indicates that the country is a temperate country; 4) tons/ha: a country's crop yield in year t in metric tons/ha (I summed all tons of crops produced in a country and divided by total cropped hectares in a country); 5) million kcals/ha: a country's crop yield in year t in millions of $\mathrm{kcals} / \mathrm{ha}$ (I summed all kcals of crops produced in a country and divided by total cropped hectares in a country); 6) soilscore: The composite soil quality score of the land that was cropped in year $\mathrm{t}$ in country $\mathrm{k}$ (on a 1 to 5 scale with lower numbers indicating better soil); 7) ha: total cropped hectares in year t in country k; 8) rice: percentage of cropped area in rice in year t in country $k ; 9)$ wheat: percentage of cropped area in wheat in year t in country k; 10) sugar: percentage of cropped area in sugarcane in year $t$ in country $k ; 11)$ grains: percentage of cropped area in coarse grains in year t in country $k$; 12) oil: percentage of cropped area in oil crops in year t in country $k$; 13) fruits: percentage of cropped area in fruits in year t in country $k ; 14)$ roots: percentage of cropped area in roots and tubers in year $t$ in country $k$; 15) other: percentage of cropped area in all other crops in year t in country $\mathrm{k} ; 16$ ) davg: The composite average daytime temperature over cropped lands during the growing season year t in country $\mathrm{k}$ (Celsius); 17) navg: The composite average nighttime temperature over cropped lands during the growing season year $\mathrm{t}$ in country $\mathrm{k}$ (Celsius); 18) pavg: The total rainfall over cropped lands during the growing season year $\mathrm{t}$ in country $\mathrm{k}(\mathrm{mm}) ; 19)$ irr: Fraction of cropped lands that are equipped for irrigation in year t in country $\mathrm{k} ; 20$ ) land: total money invested in agricultural land development divided by cropped hectares in year t in country $\mathrm{k}$ (2005 constant US \$/ha); 21) eqp: total money invested in agricultural equipment divided by cropped hectares in year t in country $\mathrm{k}$ (2005 constant US \$/ha)

\section{Dataset 3. Accuracy of decision trees}

http://dx.doi.org/10.5256/f1000research.10419.d146340

\section{Econometric model results}

Improvements in agricultural science and management, crop-mix change, and increased fertilizer use has explained most recent yield growth. When using either the long and wide datasets, time was the largest contributor to crop yield growth (both in terms of $\mathrm{Mg} \mathrm{ha}^{-1}$ and $\mathrm{M} \mathrm{kcals} \mathrm{ha}{ }^{-1}$ ) at the global and temperate region levels (Table 1 and Table 2 for the wide and long results, respectively). (Unless otherwise stated, we discuss mean results in the text.) At the global level, the time counterfactual's integral makes up approximately $57 \%$ or $72 \%$ of the $\mathrm{Mg}$ gap (always wide and long results, respectively, unless otherwise stated) and $37 \%$ or $47 \%$ of the kcal gap. In the time counterfactual, we held the year variable fixed at 1975 . In the temperate region, the time counterfactual makes up $79 \%$ or $90 \%$ of the $\mathrm{Mg}$ gap and $62 \%$ and $67 \%$ of the $\mathrm{kcal}$ gap. At the other extreme, the time counterfactual only explains $-1.5 \%$ or $24 \%$ and $-12.5 \%$ or $18 \%$ of the tropic's $\mathrm{Mg}$ and kcal gaps, respectively.

Our econometric model's time trend jointly captures the impact of several agricultural inputs that are omitted from our global panel database. Between 1975 and the mid-2000s, agricultural technology, agriculture management science, pesticide use, and international trade of agricultural commodities (variables missing from our dataset) increased around the world ${ }^{12}$. That greater technology, better management, and more pesticides increased yield is intuitive. However, the impact of increasing globalization on yields was important as well. Greater liberalization of agricultural production policies around the world and advancements in shipping technology meant that farmers were able to access international markets at increasingly lower costs ${ }^{13}$. And this increased market access spurred greater investment in farms (e.g., 14). Further, as cropland around the world became scarcer relative to the supply of rural labor, farmers increasingly became motivated to maximize yield rather than economize on labor use (e.g., 15). The time trend crudely accounts for the joint impact of these unobserved factors on yields (including fertilizer use in the long results but not in the wide results, which explicitly includes fertilizer use). Our results make it clear that the recent growth in agricultural technology, input use, farm management, globalization, and market liberalization disproportionally benefited the farmers of more developed nations in the temperate region than it did farmers of tropical countries.

When using either the wide or long datasets, change in crop mix was the largest net contributor to yield growth in the tropics. The tropical region's integral from the crop mix counterfactual, where we kept the relative mix of crop hectarage in each country frozen at 1975 levels, makes up $55 \%$ or $61 \%$ and $58 \%$ or $65 \%$ of the tropic's Mg and kcals gaps, respectively. Between 1975 and 2007 oil crops, sugarcane, roots and tubers, and fruit became a larger part of cropped area in the tropic region (Figure 3). According to the econometrically estimated yield models (Supplementary Table 1 and Supplementary Table 2), replacing wheat and other grain production with sugarcane, roots and tubers, and fruit production was 
Table 1. The size of the area between the expected yield curve and a counterfactual's yield curve when fertilizer is included as an input ("wide" model results). The global model uses all countries while the regional models only use countries in the given region. The "Low" estimates are calculated with the $25^{\text {th }}$ percentile annual yield estimates in each country. The "High" estimates are calculated with the $75^{\text {th }}$ percentile annual yield estimates in each country. The cells in black indicate the integral if all agricultural inputs other than weather are fixed at 1975 levels (the numeraire counterfactuals; see Figure 1 and Figure 2). All other cells have an increasingly dark shade of green (red) as the integrals get more positive (negative). Pure white occurs at 0.

\begin{tabular}{|c|c|c|c|c|c|c|c|}
\hline \multirow[b]{2}{*}{ Counterfactual } & \multirow[b]{2}{*}{ Model } & \multicolumn{3}{|c|}{ Mg ha $^{-1}$} & \multicolumn{3}{|c|}{ M kcals ha ${ }^{-1}$} \\
\hline & & Low & Mean & High & Low & Mean & High \\
\hline \multirow{3}{*}{ No change other than weather } & Globe & 25.00 & 25.49 & 25.63 & 67.17 & 65.72 & 71.60 \\
\hline & Temperate & 33.46 & 33.51 & 32.74 & 64.95 & 65.24 & 64.97 \\
\hline & Tropics & 27.62 & 28.13 & 31.43 & 90.60 & 92.04 & 103.76 \\
\hline \multirow{3}{*}{ Soil quality of cropland } & Globe & 0.39 & -0.08 & -0.17 & -9.55 & -0.14 & 3.61 \\
\hline & Temperate & -0.14 & 0.07 & -0.30 & 0.78 & 0.23 & 0.69 \\
\hline & Tropics & 1.68 & -0.03 & 0.04 & 5.51 & 0.54 & -1.23 \\
\hline \multirow{3}{*}{ Area cultivated } & Globe & -3.46 & -3.35 & -3.16 & -3.21 & 3.51 & 5.33 \\
\hline & Temperate & -2.99 & -1.95 & -2.61 & 6.38 & 7.89 & 7.30 \\
\hline & Tropics & -0.37 & -1.92 & -2.06 & 3.11 & -3.85 & -4.93 \\
\hline \multirow{3}{*}{ Daytime growing season temp. } & Globe & -1.02 & -1.12 & -0.72 & -1.67 & -2.86 & 3.50 \\
\hline & Temperate & -0.37 & -0.05 & 0.24 & -0.47 & 0.24 & -0.28 \\
\hline & Tropics & -1.72 & -2.95 & -1.24 & -12.72 & -9.55 & -8.68 \\
\hline \multirow{3}{*}{ Nighttime growing season temp. } & Globe & 1.56 & 1.24 & 1.98 & -4.14 & 3.25 & 9.06 \\
\hline & Temperate & -2.29 & -0.99 & -0.91 & -2.00 & -1.94 & -2.77 \\
\hline & Tropics & 3.96 & 2.80 & 2.73 & 11.39 & 9.74 & 35.54 \\
\hline \multirow{3}{*}{ Growing season precipitation } & Globe & -0.03 & -0.01 & 0.51 & 2.63 & -0.02 & 2.61 \\
\hline & Temperate & -0.95 & -0.10 & 0.69 & -0.43 & -0.21 & -1.16 \\
\hline & Tropics & 0.75 & 0.01 & 0.29 & -6.17 & 0.01 & 15.42 \\
\hline \multirow{3}{*}{ Crop mix } & Globe & 6.40 & 5.91 & 6.30 & 18.42 & 22.49 & 25.00 \\
\hline & Temperate & 1.01 & 0.54 & 1.71 & 5.99 & 7.09 & 5.49 \\
\hline & Tropics & 15.82 & 15.52 & 16.10 & 53.80 & 53.71 & 61.18 \\
\hline \multirow{3}{*}{ Irrigation capability } & Globe & 0.61 & 0.27 & 0.25 & 0.77 & 0.67 & 3.54 \\
\hline & Temperate & 1.31 & 1.14 & 1.70 & -0.32 & 1.31 & 1.22 \\
\hline & Tropics & 0.77 & 0.50 & 0.87 & -10.48 & 0.27 & 4.08 \\
\hline \multirow{3}{*}{$\begin{array}{l}\text { Investment in land and } \\
\text { equipment }\end{array}$} & Globe & 0.51 & 0.01 & -0.23 & 3.43 & -0.25 & 3.91 \\
\hline & Temperate & -1.23 & -0.24 & 0.48 & -1.69 & -0.45 & -2.62 \\
\hline & Tropics & 3.10 & 1.71 & 3.30 & 9.14 & 7.03 & -2.96 \\
\hline \multirow{3}{*}{ Time } & Globe & 14.87 & 14.46 & 14.96 & 24.55 & 24.07 & 21.91 \\
\hline & Temperate & 25.99 & 26.40 & 27.03 & 40.93 & 40.63 & 39.84 \\
\hline & Tropics & 0.30 & -0.43 & 0.61 & -10.13 & -11.54 & -16.39 \\
\hline \multirow{3}{*}{ Fertilizer } & Globe & 7.70 & 8.17 & 8.04 & 9.02 & 15.09 & 20.12 \\
\hline & Temperate & 6.81 & 7.54 & 8.50 & 6.45 & 7.88 & 5.67 \\
\hline & Tropics & 11.20 & 10.56 & 10.88 & 35.74 & 38.72 & 29.91 \\
\hline
\end{tabular}


Table 2. The size of the area between the expected yield curve and a counterfactual's yield curve when fertilizer is not an input ("Iong" model results). See the legend of Table 1 for more details.

\begin{tabular}{|c|c|c|c|c|c|c|c|}
\hline \multirow[b]{2}{*}{ Counterfactual } & \multirow[b]{2}{*}{ Model } & \multicolumn{3}{|c|}{ Mg ha-1 } & \multicolumn{3}{|c|}{ M kcals ha ${ }^{-1}$} \\
\hline & & Low & Mean & High & Low & Mean & High \\
\hline \multirow{3}{*}{ No change other than weather } & Globe & 30.17 & 30.53 & 31.34 & 78.18 & 87.65 & 84.88 \\
\hline & Temperate & 42.53 & 41.81 & 40.66 & 78.07 & 81.12 & 83.10 \\
\hline & Tropics & 37.19 & 36.76 & 37.21 & 115.27 & 121.09 & 99.66 \\
\hline \multirow{3}{*}{ Soil quality of cropland } & Globe & -1.80 & -0.38 & -1.84 & -7.80 & -0.34 & -9.57 \\
\hline & Temperate & 1.10 & 0.46 & -0.59 & -0.58 & 0.44 & 0.65 \\
\hline & Tropics & 0.91 & 1.87 & 2.56 & 4.79 & 6.55 & 7.59 \\
\hline \multirow{3}{*}{ Area cultivated } & Globe & -0.25 & -0.70 & 0.80 & 2.56 & 14.28 & 16.32 \\
\hline & Temperate & 1.93 & 2.17 & 1.31 & 13.30 & 15.00 & 17.67 \\
\hline & Tropics & -1.97 & -1.82 & -2.23 & 10.49 & 2.79 & -0.45 \\
\hline \multirow{3}{*}{ Daytime growing season temp. } & Globe & -2.36 & -1.83 & -1.06 & -8.90 & -4.09 & -7.88 \\
\hline & Temperate & -1.62 & -0.91 & -2.46 & -0.84 & -1.36 & -0.06 \\
\hline & Tropics & -3.32 & -3.76 & -3.55 & -17.06 & -12.24 & -25.26 \\
\hline \multirow{3}{*}{ Nighttime growing season temp. } & Globe & 0.73 & 1.28 & 0.87 & -2.43 & 2.93 & 9.62 \\
\hline & Temperate & -2.59 & -1.63 & -3.11 & -1.34 & -1.34 & 1.30 \\
\hline & Tropics & 4.02 & 3.61 & 4.10 & -0.49 & 9.06 & -3.58 \\
\hline \multirow{3}{*}{ Growing season precipitation } & Globe & -0.76 & -0.01 & -1.07 & -4.28 & -0.03 & -4.74 \\
\hline & Temperate & -1.12 & -0.03 & -2.72 & -2.29 & -0.20 & 0.14 \\
\hline & Tropics & 0.43 & 0.02 & 0.95 & 0.21 & -0.01 & -4.49 \\
\hline \multirow{3}{*}{ Crop mix } & Globe & 8.50 & 9.11 & 9.51 & 31.68 & 32.34 & 27.45 \\
\hline & Temperate & -1.29 & -0.27 & -0.68 & 11.16 & 8.50 & 9.03 \\
\hline & Tropics & 23.27 & 22.49 & 23.21 & 69.19 & 78.88 & 66.39 \\
\hline \multirow{3}{*}{ Irrigation capability } & Globe & -0.07 & 0.05 & -0.61 & -10.56 & 0.31 & 0.59 \\
\hline & Temperate & 1.64 & 1.73 & 0.50 & -0.48 & 1.43 & 0.96 \\
\hline & Tropics & 1.90 & 0.82 & 2.16 & -1.82 & 1.71 & 4.67 \\
\hline \multirow{3}{*}{ Investment in land and equipment } & Globe & -1.02 & 0.16 & -0.04 & -5.77 & -0.20 & -4.22 \\
\hline & Temperate & -1.19 & -0.30 & -3.34 & 2.69 & -0.54 & 2.08 \\
\hline & Tropics & 2.79 & 2.03 & 1.87 & -14.40 & 1.56 & -16.07 \\
\hline \multirow{3}{*}{ Time } & Globe & 21.57 & 22.07 & 21.18 & 38.36 & 40.97 & 33.59 \\
\hline & Temperate & 38.19 & 37.48 & 34.97 & 52.58 & 54.62 & 54.17 \\
\hline & Tropics & 8.52 & 8.78 & 8.41 & 13.49 & 21.49 & 25.82 \\
\hline
\end{tabular}

particularly important to improving overall crop yield in the tropics. The gain in yield due to this crop switching can partly be explained by a simple substitution effect: Tropical cropland was increasingly used to grow denser fruits and roots and tubers versus less dense grains. However, this also reflects a comparative advantage effect, as wheat and most grains are most effectively grown in cooler climates while fruits are most cost-effectively grown in the tropics ${ }^{16}$. In comparison to its impact in the tropics, change in crop mix in the temperate region had little impact on yield when measured in $\mathrm{Mg}$ and only slightly improved yield when measured in M kcals.
The change in a country's crop mix from 1975 to the mid-2000s was most likely driven by changes in global demand for various foodstuffs (e.g., 17,18) and the increasing globalization of crop production and trade ${ }^{12}$. As an example of the former effect, retail sales of foods with high oil and fat content increased dramatically in many countries from 1983 to 2002. Further, the number of calories that the average global person obtained from cereals fell while the number of calories they obtained from fruits and vegetables rose from 1996 to $2002^{19}$. As an example of the globalization effect, consider that the reduction of several trade barriers in the early 1990s was largely responsible for the doubling of soybean 


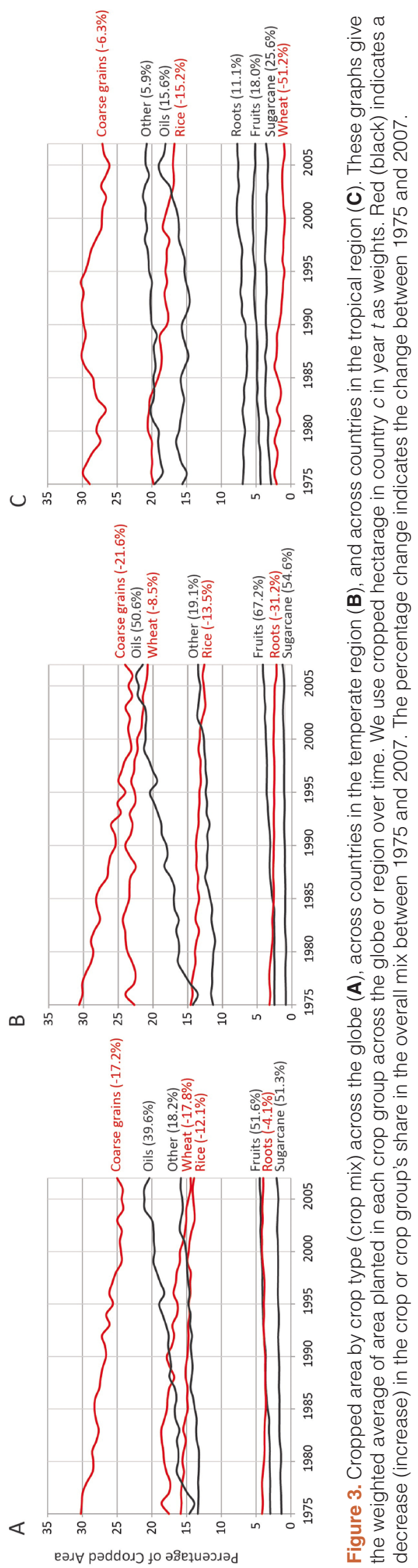


production in Brazil $^{20}$. Other potential explanations for countrylevel changes in crop mix include farmers adapting to climate change. However, there is little evidence of adaptation being a large driver of crop mix change.

Increasing fertilizer use across the globe from 1975 to 2002 (Table 3) was the next most important contributor to the steady gains in yield over that time period (only the wide dataset includes fertilizer data). When yield is measured in $\mathrm{Mg} \mathrm{ha}^{-1}$, the fertilizer counterfactual makes up $23 \%$ to $32 \%$ to $38 \%$ of the $\mathrm{Mg}$ gaps

Table 3. Mean fertilizer values at the global and tropical and temperate regions levels (kg/cropped ha). All averages are weighted by cropped area in each country in each year.

\begin{tabular}{|r|r|r|r|}
\hline & $\begin{array}{l}\text { 1975-77 } \\
\text { average }\end{array}$ & $\begin{array}{l}\text { 2000-02 } \\
\text { average }\end{array}$ & \% Change \\
\hline Globe & \multicolumn{1}{|l|}{84.17} & 128.56 & $52.73 \%$ \\
\hline Temperate & 99.64 & 152.82 & $53.37 \%$ \\
\hline Tropics & 34.37 & 68.46 & $99.16 \%$ \\
\hline
\end{tabular}

(the temperate, global, and tropics $\mathrm{Mg}$ gaps, respectively). When yield is measured in $\mathrm{M}$ kcals $\mathrm{ha}^{-1}$, fertilizer makes up $12 \%$ to $23 \%$ to $42 \%$ of the kcals gaps (again, the temperate, global, and tropics $\mathrm{Mg}$ gaps, respectively). Further, the time trend no longer has a positive effect on the tropical yield when using the wide dataset. In fact, the time counterfactual produces a negative kcal gap in the tropics.

Recent climate change slightly dampened yield growth. Compared to time, crop mix, and fertilizer use, the impact of the other agricultural inputs on recent global and regional yield was much less significant in terms of magnitude. When using the long or wide datasets, recent increases in daytime growing season temperatures (DGSTs; Table 4) negatively affected global and regional yields. When yield is measured in $\mathrm{Mg} \mathrm{ha}^{-1}$, the DGST counterfactual makes up $-4 \%$ or $-6 \%$ of the global $\mathrm{Mg}$ gap (as before, the order is always wide and long results, respectively, unless otherwise stated). When yield is measured in $\mathrm{M} \mathrm{kcals} \mathrm{ha}^{-1}$, the DGST counterfactual makes up $-4 \%$ or $-5 \%$ of the global kcals gap. In the DGST counterfactual we fixed DGSTs around the world at 1975-1977 averages. The negative impact of increasing DGSTs on global yield was almost entirely explained by its drag on tropical yields; the impact of increasing DGSTs on temperate region yields was almost non-existent.

Table 4. Mean values at the global and tropical and temperate regions levels. All averages are weighted by cropped area in each country in each year.

\begin{tabular}{|c|c|c|c|c|c|c|}
\hline & $\begin{array}{l}1975-77 \\
\text { average }\end{array}$ & $\begin{array}{l}2005-07 \\
\text { average }\end{array}$ & $\%$ Change & $\begin{array}{l}1975-77 \\
\text { average }\end{array}$ & $\begin{array}{l}2005-07 \\
\text { average }\end{array}$ & $\%$ Change \\
\hline & \multicolumn{3}{|c|}{$\begin{array}{l}\text { Hectares } \\
\text { (Millions) }\end{array}$} & \multicolumn{3}{|c|}{$\begin{array}{c}\text { Irrigation } \\
\text { (Equipped ha/cropped ha) }\end{array}$} \\
\hline Globe & 7.23 & 8.86 & $22.54 \%$ & 0.199 & 0.253 & $26.87 \%$ \\
\hline Temperate & 11.39 & 12.54 & $10.10 \%$ & 0.233 & 0.318 & $36.55 \%$ \\
\hline \multirow[t]{2}{*}{ Tropics } & 3.57 & 5.63 & $57.55 \%$ & 0.099 & 0.122 & $23.91 \%$ \\
\hline & \multicolumn{3}{|c|}{$\begin{array}{l}\text { Soil score } \\
\text { (a lower score means better nutrient } \\
\text { availability and retention capacity) }\end{array}$} & \multicolumn{3}{|c|}{$\begin{array}{c}\text { Equipment investment } \\
\text { (\$ M (2005)/10,000 cropped ha) }\end{array}$} \\
\hline Globe & 1.51 & 1.56 & $2.82 \%$ & 8.41 & 9.19 & $9.30 \%$ \\
\hline Temperate & 1.39 & 1.38 & $-0.38 \%$ & 10.90 & 12.82 & $17.60 \%$ \\
\hline \multirow[t]{2}{*}{ Tropics } & 1.89 & 1.92 & $1.63 \%$ & 1.22 & 1.95 & $59.54 \%$ \\
\hline & \multicolumn{3}{|c|}{$\begin{array}{c}\text { Growing season daytime temp. } \\
\text { (Celsius) }\end{array}$} & \multicolumn{3}{|c|}{$\begin{array}{l}\text { Land development investment } \\
\text { (\$ M (2005)/10,000 cropped ha) }\end{array}$} \\
\hline Globe & 27.68 & 29.06 & $4.98 \%$ & 10.84 & 11.85 & $9.32 \%$ \\
\hline Temperate & 26.88 & 28.06 & $4.40 \%$ & 9.81 & 11.24 & $14.58 \%$ \\
\hline \multirow[t]{2}{*}{ Tropics } & 29.87 & 30.90 & $3.45 \%$ & 14.08 & 13.40 & $-4.84 \%$ \\
\hline & \multicolumn{3}{|c|}{$\begin{array}{c}\text { Growing season nighttime temp } \\
\text { (Celsius) }\end{array}$} & \multicolumn{3}{|c|}{$\begin{array}{c}\text { Growing season precipitation } \\
(\mathrm{mm})\end{array}$} \\
\hline Globe & 16.87 & 18.31 & $8.53 \%$ & 115.16 & 113.09 & $-1.80 \%$ \\
\hline Temperate & 15.90 & 17.05 & $7.23 \%$ & 125.83 & 128.69 & $2.27 \%$ \\
\hline Tropics & 19.64 & 20.77 & $5.75 \%$ & 158.76 & 162.10 & $2.11 \%$ \\
\hline
\end{tabular}


All else equal, warm days and cool nights allow for vigorous plant growth during the day and efficient plant respiration at night ${ }^{21-24}$. In contrast, warmer nighttime temperatures cause more wasteful respiration and less energy for growth during the day, all else equal. Therefore, we were surprised to find that increasing nighttime growing season temperatures (NGSTs) at the global and tropical region scales (Table 4) were associated with a boost in yields. The NGST counterfactual makes up $10 \%$ of tropic's Mg and kcal gaps. However, in the temperate region we find evidence of the expected impact of increasing NGS temperatures on yield: the NGST counterfactual makes up $-3 \%$ or $-4 \%$ and $-3 \%$ or $-2 \%$ of the temperate region's $\mathrm{Mg}$ and kcal gaps, respectively. Changes in growing season precipitation had no effect on global or regional yields.

Recent change in cropped soil quality and cropland footprint had a negligible effect on yield growth. Recent changes in the quality of cropped land around the world have had a mixed effect on yield growth. One way we measure the change in the quality of land a country crops on is by measuring the change in its cropped soil's nutrient availability and retention capacity as its cropland footprint shifts across the landscape ${ }^{25}$. We also measure a country's extensive change in footprint by tracking its net areal change in cropland over time. The extensive change in cropped area is a catch-all for the change in land quality conditions not measured by the change in the nutrient availability and retention capacity of cropped soils. We assume that a country's most productive land has long been used for crops and net growth in cropland extent since 1975 will have had a negative impact on yield as only more marginal lands were available for cropping after 1975. For example, most of the globe's 1975 to mid-2000s growth in cropland extent occurred in the tropics (Table 4). Further, the decline in the overall quality of cropped soil has been more dramatic in the tropics as more and more tropical forest area and their poor soils have been used for crops since $1975^{26}$.

A general worsening in the nutrient availability and retention capacity of cropped soils across the globe was associated with slightly lower yields (Table 1 and Table 2). However, the extent of the loss was very small (the soil quality counterfactual makes up $-0.2 \%$ to $-1.2 \%$ of global $\mathrm{Mg}$ and kcal gaps). As expected, net growth in a cropped area was associated with a decline in global and tropical $\mathrm{Mg}$ yields. Again, however, the extent of the negative impact is relatively minor (the area cultivated counterfactual makes up $-13 \%$ or $-2 \%$ to of global $\mathrm{Mg}$ gaps and $-7 \%$ or $-5 \%$ of tropical $\mathrm{Mg}$ gaps). In contrast, and contrary to expectations, net growth in cropped area was associated with an increase in global and temperate region yields when measured in $\mathrm{M} \mathrm{kcals} \mathrm{ha}^{-1}$. Again, however, the extent of the gap created by net change in cropped area in these cases is relatively small (the area cultivated counterfactual makes up $5 \%$ or $16 \%$ of global kcals gaps and $12 \%$ or $19 \%$ of temperate region kcals gaps).

The counterintuitive positive relationship between net cropland expansion and higher $\mathrm{M} \mathrm{kcal} \mathrm{ha}^{-1}$ yield in the temperate region may hold for several reasons. First, it may be that land that was marginal for crops grown earlier in the $20^{\text {th }}$ century became more suitable for the more kcal-denser crop mixes grown over the last 40 years. Second, land that was marginal given earlier technology and cultivars may have become increasingly productive, especially for kcal-rich crops, with emerging technology. Third, cropland across the world has generally become better connected to transportation infrastructure, thereby encouraging farmers to invest in their operations and potentially more than compensating for their land's quality shortcomings $\mathrm{s}^{14,27}$. Finally, we note that these counter intuitive results are less noticeable when using the wide dataset. In other words, the yield curves estimated with the long dataset may be biased upwards with respect to the area cultivated variable due to the omitted fertilizer variable.

Investment in land, machinery, and irrigation had little impact on recent yield growth. Surprisingly, investment in irrigation capacity and investment in land and equipment and machinery (Table 4) had very little effect on global and regional yields (see the irrigation capability and investment in land and equipment counterfactuals in Table 1 and Table 2). Increases in irrigation capacity had a positive effect on $\mathrm{Mg}$ and kcal yield across the globe and in both regions but no irrigation capacity counterfactual produced an integral larger than $4 \%$ of a gap. Further, investment in land and farm machinery and equipment appears to have contributed little to yield growth over time. Investment in land may have had little effect on yield because land development investment per cropped hectare only increased by $10 \%$ around the globe between 1975 and 2007 and actually fell over this time period in the tropics (Table 4). However, the lack of investment in land in the tropics was countered by a contemporaneous $60 \%$ increase in the value of farm machinery and equipment per cropped hectare in the region. The large increase in machinery and equipment use in the tropics vis-à-vis the temperate region may explain why the tropical integrals for the investment in land, machinery, and equipment counterfactual are larger than the analogous integrals for the temperate region. The investment in land, machinery, and equipment counterfactual makes up $6 \%$ of the tropic's Mg gap (with both the wide and long model estimates) and $8 \%$ or $1 \%$ of the tropic's kcal gap (with the wide and long model estimates, respectively).

Drivers of yield growth according to a decision tree analysis Before we analyzed our two panel datasets with decision trees, we first transformed them into annual change datasets. These annual change datasets begin with each country's 1975 to 1976 changes and end with each country's 2001 to 2002 changes (wide dataset) or 2006 to 2007 changes (long dataset). Further, we transformed the continuous distributions of annual change in countrylevel yields into discrete distributions of three tertiles; low annual change (L), moderate annual change (M), and high annual change $(\mathrm{H})$ (see Table 5 for an exact numerical definition of these categories).

The decision tree algorithm recursively partitions the dataset, eventually settling on $n$ sets of decision sequences that predict outcomes of L, M, and $\mathrm{H}$ ( $n$ traversals of a tree, from the "root" that contains all the data to a "leaf" that contains a subset of the data) ${ }^{28-30}$. The partitioning of the data can be constrained by one or more pruning rules. We pruned trees to make them easier to interpret and to increase our confidence in their predictive power. Here, we pruned trees by mandating that each leaf node in a tree has at least 50 records that support the decision sequence leading to the leaf node. In other 


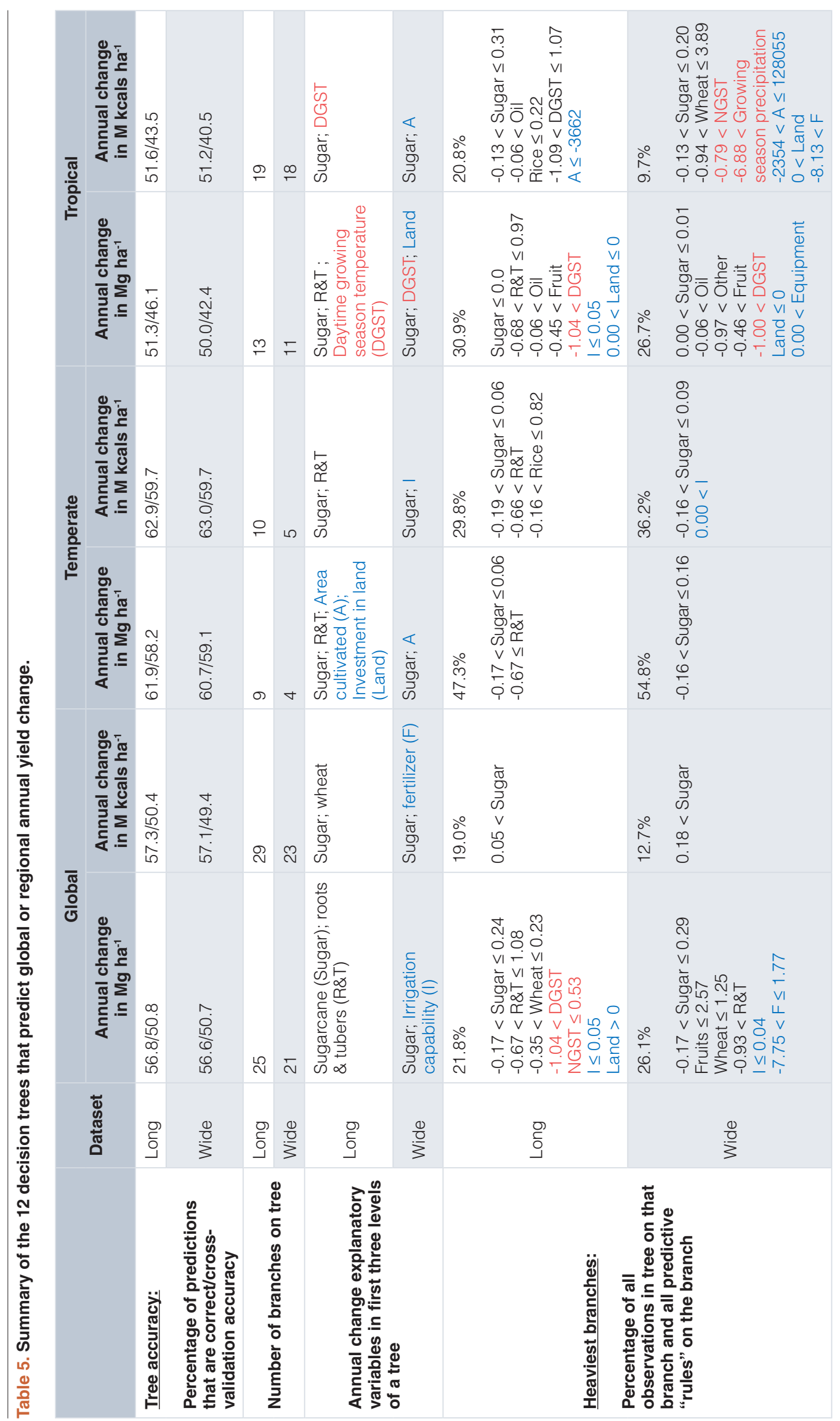




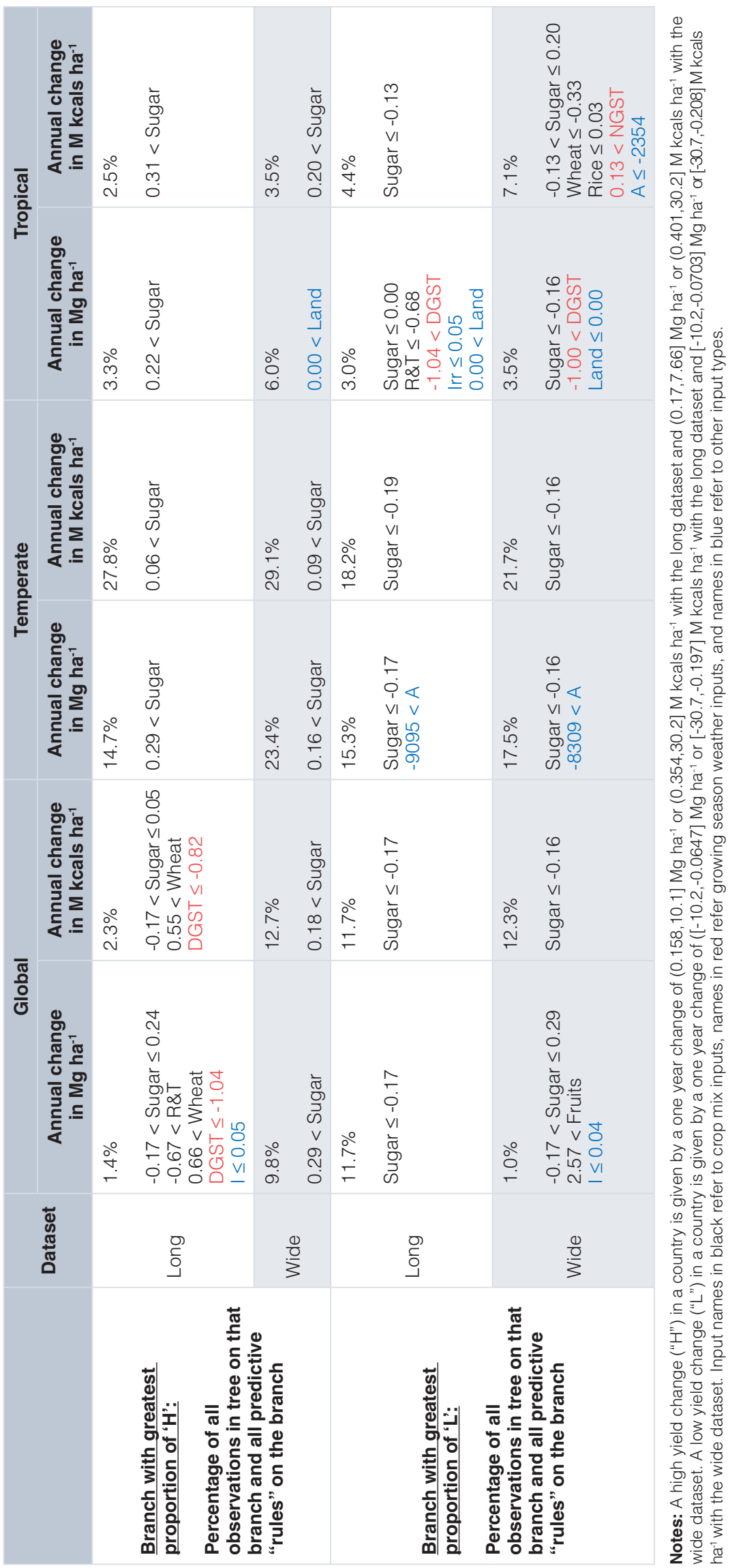


words, sets of country-level year-to-year changes in inputs could not be mapped as a branch unless at least 50 instances of that set were observed in the data. After meeting the pruning rules, the decision tree algorithm produced the sets of annual changes in agricultural inputs that best predicted whether a country had an L, $\mathrm{M}$, or $\mathrm{H}$ categorical change in annual yield.

Unique combinations of yield metric $\left\{\mathrm{Mg} \mathrm{ha}^{-1}, \mathrm{M} \mathrm{kcals} \mathrm{ha}^{-1}\right\}$, scale \{globe, temperate, tropics\}, and dataset \{wide dataset, long dataset\} means that we created 12 unique trees of annual yield change predictions. (see Supplementary Figure 1-Supplementary Figure 12). We summarize the 12 decision trees in several ways. First, we report on the accuracy and complexity of each tree (Table 5; Dataset $3^{10}$ ). Second, we list all of the inputs that are found in the first three levels of a tree. We highlight these inputs because they do the most towards predicting annual change in a country's yield. Third, we highlight the traversal in each tree with the highest number of records. These traversals indicate the annual changes in agricultural inputs that are most common across space and time. Finally, we indicate the traversals that generate the greatest proportion of high $(\mathrm{H})$ and low (L) annual country-level yield changes in a tree. These traversals give the ranges in annual input change that, respectively, best predict a high and low annual yield change in a country.

We find that the trees constructed from the wide dataset are simpler (fewer traversals) than those constructed from the long dataset and the trees constructed with the change in $\mathrm{Mg} \mathrm{ha}^{-1}$ yield metric are simpler than those constructed with the change in $\mathrm{M} \mathrm{kcal} \mathrm{ha}^{-1}$ yield metric. (The econometric analysis also indicates that the wide dataset with yield measured in $\mathrm{Mg} \mathrm{ha}^{-1}$ fits the yield model better than the other three yield measure - dataset combinations.) In terms of prediction accuracy, the trees constructed over the temperate countries are better than the trees generated over all countries and tropical countries only, and the trees generated with yield measured in M Kcals ha ${ }^{-1}$ are better than the trees generated with yield measured in $\mathrm{Mg} \mathrm{ha}^{-1}$. Therefore, annual yield changes in the temperate countries are explained by a narrower set of annual input changes than annual yield changes in the tropics. To put it another way, explanations of changes in tropical yields are messier.

Next we describe the inputs found closest to the roots of trees where the root of the tree contains all the data. We define "close to the root" as the first three levels of a tree from its root (the first three decisions). Changes in a country's crop mix - change in relative area devoted to sugarcane, roots and tubers, and wheat - appear close to the roots of all 12 trees. In particular, sugarcane is found close to the root of all 12 trees and the roots and tubers crop category is found close to the root of all three trees formed with the long dataset when yield is measured in $\mathrm{Mg} \mathrm{ha}^{-1}$. The annual change in DGSTs is close to the root of three of the four trees estimated over the tropical countries. Finally, change in cultivated area is found close to the root of the two trees estimated over the temperate countries when yield is measured in $\mathrm{Mg} \mathrm{ha}^{-1}$. Therefore, the decision trees indicate that recent annual changes in yield across the globe were most associated with changes in crop mix and that each region had idiosyncratic drivers of yield change as well.

(In the decision tree analysis we de-trended the data by using annual changes; in the fixed-effects analysis we de-trended the data by including time as an explanatory variable. This means the decision tree analysis cannot account for the various unobserved inputs that are correlated with time.)

A gain in the proportion of a country's crop mix devoted to sugarcane is the best predictor of high $(\mathrm{H})$ yield change in five of the six trees created with the wide dataset and four of the six trees created with the long dataset. Prediction of the $\mathrm{H}$ category is a bit more complicated in the global trees estimated with the long dataset. According to trees estimated with the long dataset, gains in wheat and roots and tubers in the proportional mix of a country's crop profile, modest changes in sugarcane's contribution to the proportional mix, and growing seasons that had cooler daytime temperatures than the previous growing season were most likely to have led to a high annual gain in a country's yield.

The best set of predictors for a negative change in annual yield (the $\mathrm{L}$ yield category) is a bit more expansive than the sets of best predictors for the $\mathrm{H}$ yield category. Not surprisingly, losses in proportion of a country's crop mix devoted to sugarcane are found in all tree branches with the highest proportion of L observations. In the tropics, a one-year gain in DGST and NGST were also associated with yield losses from one year to the next. Finally, an increase in a country's cultivated area from one year to the next was associated with a negative change in a temperate country's $\mathrm{Mg} \mathrm{ha}^{-1}$ yield.

Comparing econometric model results to decision tree results When we compare the decision trees (Table 5) to the econometrically estimated counterfactual results (Table 1 and Table 2) several similarities and differences emerge. First, both analyses highlight that changes in crop mix have been one of the most important contributions to the gain in crop yields over the last 40 years. The decision tree analysis also reinforces the econometric evidence that gains in DGSTs dampened gains in yields more in the tropics than in the temperate region. The trees, like the counterfactual analysis, also suggest that investment in irrigation, land, machinery, and equipment and the quality of cropped soil had little effect on yield change. The counterfactual and the decision tree analyses disagree on the importance of fertilizer use in explaining yield gains over the last 40 years, however; the counterfactual analysis deems this input more important than the decision tree analysis.

\section{Discussion}

Improvements in agricultural technology, management, and science, changes in crop mix, and increased fertilizer use were responsible for the lion's share of yield improvement around the world from 1975 to 2007. The negative yield impacts associated with increases in growing season temperatures were smaller. In some cases, the 
changes in the quality of land used for crops and cropland footprint were just as detrimental to yields as changes in climate.

\section{Suggestions for maintaining yield growth momentum}

The downward pressure on crop yields due to climate change will worsen in the future (e.g., 31). We see two paths to continued yield improvements despite this growing drag on yields. First, investment in agricultural technology, chemical inputs, management, and science in the tropics is vitally important (the so-called closing of "yield gaps"15). As indicated by the "time" counterfactuals, the tropics have not yet experienced the agricultural science and management revolution that the temperate region has. Second, if each country can increasingly specialize in the crops best suited for their (changing) climate and trade for the rest of their crop needs, then the spatial allocation of crops will become more efficient. For example, our results suggest the continued divestment in grain production in the tropics and greater investment in grain production in the temperate zone would do much to boost food production in the future. Further, greater fruit and sugarcane production in the tropics relative to the temperate zone would also help accelerate food production $^{32}$. More trade liberalization and the reduction or even elimination of national crop subsidy programs will make it easier for each country to grow the crops best suited for their soilclimate conditions ${ }^{13}$.

Several suggested paths to greater food production are not supported by our analysis. Cropland extensification contributed little to yield gains in the immediate past and are not likely to do so in the future $^{27}$. Instead, switching to more climate-appropriate crops, using more fertilizers, chemicals and improved cultivars, and improving the nutrient retention capability of already existing cropland appears to be a more effective strategy for increasing worldwide yields and, ultimately, food production (i.e., land sparing versus land sharing; 33). This strategy would also leave more land for nature in an increasingly populated world. Further, we are also skeptical that an emphasis on investment in infrastructure in of itself (i.e., machinery and irrigation capacity) will significantly increase yields in the future; these investments did not do much to boost crop production in the recent past. Machinery that is compatible with precision agriculture (i.e., technology) is likely to be more effective than just more tractors and other machinery. Of course, the recommendation on investment in irrigation could change if climate change severely disrupts current rainfall patterns.

\section{Analysis limitations}

This analysis is limited by several data issues. First, our treatment of weather data (see Materials and Methods) did not allow us to isolate changes in growing season weather due to spatial reallocation of cropland versus changes in the atmospheric system. Separating these trends would help us better understand the effect of recent climate change on crop yields around the world. Another shortcoming of this analysis is that it does not specifically account for farmer reaction to climate change; this omission could bias our results. For example, if the changes in the spatial pattern of production and crop choice were partially affected by climate change, then we have underestimated the impact of climate change and overestimated the impact of crop choice and cropped-footprint change on recent yield trends. In addition, we are missing data for all countries that were in the Soviet Union and many Warsaw Pact countries (e.g. Poland and
Hungary). One of the data sources we used to construct our panel datasets does not contain a consistent set of data back to 1975 for these countries. Most of these countries are in the temperate region. Therefore, our analysis, especially the temperate region analysis, could be biased due to the omission of these countries from the dataset. Further, the source of our gridded crop maps stopped providing annual grid cell maps of global cropland beyond $2007^{34}$. Thus our dataset ends with 2007 data and cannot be extend into the early 2010s. Finally, to conduct this analysis, we either had to summarize the native grid-level data on cropped soil quality and growing season weather at the country level or we had to decompose the native country-level data on production, crop mix, and investment to the grid-cell level. We used the former approach.

A limitation of our decision tree analysis is that trees are constructed in a "greedy" fashion, iteratively splitting on the most powerful agricultural inputs (in a predictive sense) as the branches are built; this can lead to suboptimal trees when there are nonlinear interactions among the variables. Quinlan's C4.5 algorithm ${ }^{28}$ for the decision tree approach strives to mitigate the biasing effect of the iterative tree-building approach by repeatedly building a tree with a subset of the data and assessing its quality on the held-out data to find the most robust trees; the RWeka decision-tree packaged used for this analysis is a slightly updated version of C4.5. Additionally, we could do more to explore the sensitivity of tree results to different transformations of the data, for example, whether the trees would have greater explanatory power if change in yield outcomes were transformed to a discrete distribution of four categories instead of three.

\section{Materials and methods}

\section{Statistical analysis}

First, we used the method of least squares to estimate a fixed effects model of annual per hectare crop yield at the country level from years $\underline{t}$ through $\bar{t}$.

$$
Y_{c t}=\alpha_{c}+\beta_{0}+\boldsymbol{\beta}_{1} \mathbf{X}_{c t}+\boldsymbol{\beta}_{2} \mathbf{K}_{c t}+\beta_{3} A_{c t}+\beta_{4} S_{c t}+\beta_{5} I_{c t}+\beta_{6} \mathbf{Z}_{c t}+\beta_{7} t+\beta_{8} F_{c t}
$$

where $Y_{c t}$ is the production of all crops grown in country $c$ in harvest year $t$, measured either in metric tons $(\mathrm{Mg})$ or millions of kilocalories (M kcals), divided by harvested hectares in country $c$ in harvest year $t$ (harvest year $t$ refers to crops harvested in year $t$, but not necessarily planted in year $t$; for example, grain can be planted in October and harvested the next March in many southern hemisphere countries). Further, $\alpha_{c}$ is the fixed effect intercept for country $c, \mathbf{X}_{c t}$ is a vector of harvested hectare percentages across crop or crop groups in country $c$ in harvest year $t$ (collectively $\mathbf{X}_{c t}$ gives a country's "crop mix" in harvest year $t$; see the Supplementary Methods for more on $\left.\mathbf{X}_{c t}, 11\right), \mathbf{K}_{c t}$ contains variables that measure investment in agricultural land and agricultural machinery and equipment per harvested hectare $c$ in harvest year $t$ (11; http://faostat3.fao.org/home/E) $A_{c t}$ is the harvested or cropped hectarage in country $c$ in year $t^{11}, S_{c t}$ summarizes the quality of soil used to grow crops in country $c$ in harvest year $t^{25}, I_{c t}$ is the percentage of harvested area equipped for irrigation in $c$ in harvest year $t^{11}, \mathbf{Z}_{c t}$ is a vector of statistics that summarize the weather that occurred over country $c$ 's cropland during the growing season of harvest year $t^{8,9}$, and $F_{c t}$ measures $\mathrm{kg} \mathrm{ha}^{-1}$ of fertilizers used in country $c$ in year $t^{11}$. 
The land investment variable in vector $\mathbf{K}_{c t}$ measures major improvements in the quantity, quality or productivity of land or prevention of deterioration. Activities such as land clearance, land contouring, creation of wells and watering holes are integral to the land improvement. The concept of land improvement includes 1) field improvements undertaken by farmers (e.g., making boundaries, irrigation channels) and 2) other activities undertaken by government and other local bodies such as irrigation works, soilconservation works, and flood-control structure. The machinery and equipment investment variable in vector $\mathbf{K}_{c t}$ measures the value of tractors, harvesters and thrashers, milking machines and hand tools in a country.

See the section 'Creating country-level data for crop yield model and decision tree analysis' for more information on how we constructed the variables in the vector $\mathbf{Z}_{c t}$.

In the estimate of model (1) using the "long" dataset (Dataset $2^{9}$ ) $F_{c t}$ is not included and time $\underline{t}$ equals 1975 and time $\bar{t}$ equals 2007. In the estimate of model (1) using the "wide" dataset (Dataset $1^{8}$ ) $F_{c t}$ is included and time $\underline{t}$ equals 1975 and time $\bar{t}$ equals 2002. We estimate the long and wide versions of model (1) with all countries, tropical countries only, and temperate countries only. A country's regional affiliation is defined by the latitude of the country's capital and the Tropics of Cancer and Capricorn. Model (1) was estimated with the reg command in Stata 12.1. See Supplementary Table 1 and Supplementary Table 2 for estimates of model (1), including estimated standard errors and p-values. Stata code and related databases can be found in Supplementary materials under Stata Files.

\section{Estimating the overall contribution of an agriculture} production input on 1975 to mid-2000s global or regional crop yield

We built expected yield curves for country $c, \hat{Y}_{c t}$ for years $\underline{t}$ through $\bar{t}$, by running the country's input data from years $\underline{t}$ to $\bar{t}$ through an estimate of model (1),

$$
\hat{Y}_{c t}=\hat{\alpha}_{c}+\hat{\beta}_{0}+\hat{\boldsymbol{\beta}}_{1} \mathrm{X}_{c t}+\hat{\boldsymbol{\beta}}_{2} \mathbf{K}_{c t}+\hat{\beta}_{3} A_{c t}+\hat{\beta}_{4} S_{c t}+\hat{\beta}_{5} I_{c t}+\hat{\beta}_{6} \mathbf{Z}_{c t}+\hat{\beta}_{l} t+\hat{\beta}_{8} F_{c t}
$$

where a "^" indicates an estimate (see Supplementary Table 1 and Supplementary Table 2 for estimated coefficients). Each country has eight expected yield curves, one for each unique combination of yield measure $\left\{\mathrm{Mg} \mathrm{ha}^{-1}, \mathrm{M} \mathrm{kcals} \mathrm{ha}^{-1}\right\}$, scale $\{$ globe, appropriate region $\}$, and dataset $\{$ long, wide $\}$. Using these country-level yield curves we calculated four expected global yield curves, one for each unique combination of yield $\left\{\mathrm{Mg} \mathrm{ha}^{-1}, \mathrm{M} \mathrm{kcals} \mathrm{ha}^{-1}\right\}$ and dataset $\{$ long, wide $\}$ and eight expected regional yield curves, one for each unique combination of yield measure $\left\{\mathrm{Mg} \mathrm{ha}^{-1}, \mathrm{M} \mathrm{kcals} \mathrm{ha}^{-1}\right\}$, scale \{temperate, tropics\}, and dataset \{long, wide\}. To construct a global or regional yield curve, $\hat{Y}_{r t}$ for years $\underline{t}$ through $\bar{t}$, we averaged $\hat{Y}_{c t}$ for each year $t$ across all $c$ in $r$ (globe, temperate, tropics) weighed by each country's cropped hectarage in year $t$,

$$
\hat{Y}_{r t}=\sum_{c \in r} \frac{A_{c t} \hat{Y}_{c t}}{A_{c t}}
$$

In Figure 1, we present the global $\hat{Y}_{r t}$ for years 1975 through 2007 (the long dataset) where yield is measured in $\mathrm{Mg} \mathrm{ha}^{-1}$ (black solid curve in Figure 1A) and $\mathrm{M}$ kcals ha-1 (black solid curve in Figure 1B).

We built counterfactual yield curves for country $c, \tilde{Y}_{c t}$ for years $\underline{t}$ through $\bar{t}$, by running the country's input data from years $\underline{t}$ to $\bar{t}$ through an estimate of model (1), holding one or more of $c$ 's inputs fixed at 1975 levels (the exception is a growing season weather counterfactual; in those cases, we fix the appropriate input at the 1975-1977 annual average). Each country has 84 counterfactual yield curves for the years $\underline{t}$ through $\bar{t}$, one for each unique combination of yield measure $\left\{\mathrm{Mg} \mathrm{ha}^{-1}, \mathrm{M} \mathrm{kcals} \mathrm{ha}^{-1}\right\}$, scale globe, appropriate region\}, and 10 counterfactuals with the long dataset and 11 counterfactuals with the wide dataset. Using these country-level counterfactual yield curves, we calculated 42 counterfactual global-yield curves, one for each unique combination of yield measure $\left\{\mathrm{Mg} \mathrm{ha}^{-1}, \mathrm{M} \mathrm{kcals} \mathrm{ha}^{-1}\right\}$ and 10 counterfactuals with the long dataset and 11 counterfactuals with the wide dataset and 84 expected regional yield curves, one for each unique combination of yield measure $\left\{\mathrm{Mg} \mathrm{ha}^{-1}, \mathrm{M} \mathrm{kcals} \mathrm{ha}^{-1}\right\}$, scale \{temperate, tropics $\}$, and 10 counterfactuals with the long dataset and 11 counterfactuals with the wide dataset. To construct a global or regional counterfactual yield curve, $\tilde{Y}_{r t}$ for years $\underline{t}$ through $\bar{t}$, we averaged $\tilde{Y}_{r t}$ for each year $t$ across all $c$ in $r$, weighed by each country's cropped hectarage in year $t$,

$$
\tilde{Y}_{r t}=\sum_{c \in r} \frac{A_{c t} \tilde{Y}_{c t}}{A_{c t}}
$$

where $\boldsymbol{A}_{c t}=\boldsymbol{A}_{c, 1975}$ for all $t$ in the numeraire and "area cultivated" counterfactuals. In Figure 1, we present the global $\tilde{Y}_{r t}$ for the numeraire counterfactual (all inputs other than weather inputs are fixed at 1975 levels) for years 1975 through 2007 (the long dataset) where yield is measured in $\mathrm{Mg} \mathrm{ha}^{-1}$ (blue solid curve in Figure 1A) and $\mathrm{M}$ kcals ha ${ }^{-1}$ (blue solid curve in Figure 1B).

In the mean columns of Table 1 and Table 2 we present the counterfactual integrals,

$$
\lambda_{q m r d}=\sum_{t=\underline{\underline{Y}}}^{\bar{t}} \hat{Y}_{t m r d}-\tilde{Y}_{q m r r d}
$$

where $q$ indexes the counterfactual, $m$ indicates yield measure $\left\{\mathrm{Mg} \mathrm{ha}{ }^{-1}, \mathrm{M} \mathrm{kcals} \mathrm{ha}{ }^{-1}\right\}, r$ indicates scale \{globe, temperate, tropics\}, and $d$ indicates dataset \{long, wide\} (Figure 2). To normalize these integrals we also present the fraction of the numeraire counterfactual integral, $\lambda_{\text {conterfactual }, m, r, d}$, that counterfactual $q$ 's integral "explains,"

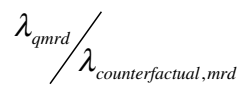

where we call $\lambda_{\text {counterfactual,mrd }} r$ 's " $m$ " gap using dataset $d$.

The counterfactual analyses were conducted with MATLAB R2013a. MATLAB code and related databases can be found in Supplementary materials under MATLAB Code for Table 1 and Table 2.

\section{Sensitivity analyses}

We generated the "low" and "high" results for each $q, m, r$, and $d$ counterfactual combination in the following manner (Table 1 
and Table 2). First, we created 1000 unique vectors of model (1) coefficients by randomly drawing from the multivariate normal distribution with a mean of $\left[\hat{\beta}_{0}, \hat{\boldsymbol{\beta}}_{1}, \hat{\boldsymbol{\beta}}_{2} \hat{\beta}_{3}, \hat{\beta}_{4}, \hat{\beta}_{5}, \hat{\boldsymbol{\beta}}_{6}, \hat{\beta}_{7}, \hat{\beta}_{8}\right]$ (the estimated vector of beta coefficients) and a covariance matrix of,

$$
\left(\sigma \sqrt{\frac{N}{\chi_{N}^{2}}}\right)^{2} \mathrm{vcov}
$$

where $\sigma$ is estimated model (1)'s root mean square error, $N$ is the number of observations in the dataset, $\chi_{N}^{2}$ is a random variable with a chi-square distribution with $N$ degrees of freedom, and $v \operatorname{cov}$ is estimated model (1)'s variance-covariance matrix for all $\beta$ 's. (We do not vary the estimated $\alpha_{c}$ coefficients.)

Second, using the 1000 randomly generated $\boldsymbol{\beta}$ coefficient vectors, we generated 1000 values of $\hat{Y}_{c t m d}$ for all $c$ and $t$ for each unique $m$ and $d$ combination and 1000 values of $\tilde{Y}_{q c t m d}$ for all $c$ and $t$ for each unique $q, m$, and $d$ combination. Third, we generated expected $25^{\text {th }}$ and $75^{\text {th }}$ percentile yield curves for each country and each unique $m$ and $d$ combination by selecting the $25^{\text {th }}$ percentile and $75^{\text {th }}$ percentile values of $\tilde{Y}_{c t m d}$ at each $t$. Fourth, we generated counterfactual $25^{\text {th }}$ and $75^{\text {th }}$ percentile yield curves for each country and each unique $q, m$, and $d$ combination by selecting the $25^{\text {th }}$ percentile and $75^{\text {th }}$ percentile values of $\tilde{Y}_{q c t m d}$ at each $t$. Fifth, we calculated a region or the globe's expected percentile yield in year $t$ with,

$$
\begin{aligned}
& \hat{Y}_{t m r d}^{25}=\sum_{c \in r} \frac{A_{c t} \hat{Y}_{c t m d}^{25}}{A_{c t}} \\
& \hat{Y}_{t m r d}^{75}=\sum_{c \in r} \frac{A_{c t} \hat{Y}_{c t m d}^{75}}{A_{c t}}
\end{aligned}
$$

for each unique $m$ and $d$ combination where the superscripts " 25 " and " 75 " indicate the $25^{\text {th }}$ and $75^{\text {th }}$ percentile, respectively. Sixth, we calculated the globe or region's counterfactual percentile yield in year $t$ with,

$$
\begin{aligned}
\tilde{Y}_{q t m r d}^{25} & =\sum_{c \in r} \frac{A_{c t} \tilde{Y}_{q c t m d}^{25}}{A_{c t}} \\
\tilde{Y}_{q t m r d}^{75} & =\sum_{c \in r} \frac{A_{c t} \tilde{Y}_{q c t m r d}^{75}}{A_{c t}}
\end{aligned}
$$

for each unique $q, m$ and $d$ combination. Finally, in the low and high columns of Table 1 and Table 2 we present the percentile counterfactual integrals for a given region $r$,

$$
\begin{aligned}
& \lambda_{\text {qmrd }}^{25}=\sum_{t=\underline{t}}^{\bar{t}} \hat{Y}_{t m r d}^{25}-\tilde{Y}_{q t m r d}^{25} \\
& \lambda_{\text {qmrd }}^{75}=\sum_{t=\underline{t}}^{\bar{t}} \hat{Y}_{t m r d}^{75}-\tilde{Y}_{q t m r d}^{75}
\end{aligned}
$$

\section{Decision tree analysis}

We constructed decision trees using the RWeka package in $\mathrm{R}$ (RWeka 0.4-24 and RWekajars 3.7.12.-1) and J48 classifiers in particular. These are a reimplementation of Quinlan's C4.5 algorithm ${ }^{28}$. We evaluated trees for prediction accuracy using a 10 -fold cross-validation strategy. Decision trees are given in Supplementary Figure 1-Supplementary Figure 12, and the results are summarized in Table 5. In the analysis reported here, "leaf nodes" (the resulting subsets of the data after the branching of the tree on decision variables) were required to contain at least 50 observations, using the $\mathrm{M}$ option to control the minimum number of instances per leaf. This approach was used to yield trees with higher human interpretability as well as higher prediction accuracy. While 50 is somewhat arbitrary, we explored other values and empirically found it to lead to high prediction accuracy and greater interpretability in the resulting trees. (Interestingly, this approach also worked better for this data than using the C option to control the "confidence" in the pruned trees.)

\section{Creating country-level data for crop yield model and decision tree analysis}

To create country-level summary statistics of the quality of cropped soil $\left(S_{c t}\right)$ and growing season weather over cropland (contained in vector $\mathbf{Z}_{\mathrm{ct}}$ ) in each country in each harvest year $t$ we used annual global grid cell maps of cropped land ${ }^{34}$ along with gridded global maps of soil quality ${ }^{25}$, monthly weather ${ }^{8}$, and growing season months ${ }^{9}$. (Ramankutty and Foley stopped updating annual global grid-cell maps of cropped land after releasing the 2007 data. Thus, our dataset ends with 2007 data.) By combining the gridded maps on soil, weather, and growing season months with gridded cropland maps we were able to create summary statistics that preserved the observed spatial heterogeneity in agronomic conditions across a county in any given year. For example, consider the landscape in Figure 4. Suppose the square landscape represents a country. Assume the large number in each grid cell in Figure 4A represents the number of cropland hectares in that cell in harvest year $t$ (the small number in the corner of a cell is its ID number). In Figure 4B each cell's nutrient availability score is given where a 1 indicates 'No or slight nutrient constraint', 2 indicates 'moderate nutrient constraint', 3 indicates 'severe nutrient constraint', 4 indicates 'very severe nutrient constraint', and 5 indicates 'mainly non-soil' (in other words, lower scores mean better soil quality; see 25. Nutrient availability $\left(N_{c t}\right)$ is decisive for successful lowlevel-input farming and, in some cases, intermediate-input-level farming. A country's composite nutrient availability score on cropland in harvest year $t$ is the weighted average of the nutrient availability scores across all cropland area in the country in harvest year $t$ or,

$$
N_{c t}=\sum_{j \in c} A_{j t} N_{j} / \sum_{j \in c} A_{j t}
$$

where $j \in c$ is the set of grid cells in country $c, N_{j}$ is grid cell $j$ 's nutrient availability score, and $A_{j t}$ is grid cell $j$ 's cropland area in harvest year $t^{34}$. In the illustrative country represented in Figure 4 $N_{c t}$ is equal to,

$N_{c t}=\frac{1 \times 100+2 \times 1000+3 \times 500+2 \times 100+\ldots+3 \times 700}{100+1000+500+100+\ldots+700}=2.28$

We use the same method to calculate a country's nutrient retention score, given by $U_{c t}$. Nutrient retention capacity is of particular importance for the effectiveness of fertilizer applications and is therefore of special relevance for intermediate and high input 


\begin{tabular}{|c|c|c|c|}
\hline 0 & 100 & 0 & 0 \\
\hline 1000 & 500 & 0 & 0 \\
\hline 100 & 700 & 500 & $0_{12}$ \\
\hline 1000 & 1000 & 800 & 700 \\
\hline
\end{tabular}

\begin{tabular}{|c|c|c|c|}
\hline 0 & 1 & 0 & 0 \\
\hline 2 & 3 & 0 & 0 \\
\hline 2 & 1 & 4 & 0 \\
\hline 1 & 1 & 5 & 3 \\
\hline
\end{tabular}

Figure 4. Illustration of the calculation of the soil score for a country. Harvested hectares in each grid cell in an illustrative country (A) where the small numbers in the corner of a grid cell indicate cell ID. Nutrient availability score $\left(N_{c t}\right)$ in each grid cell (B) where 1 indicates 'No or slight nutrient constraint', 2 indicates 'moderate nutrient constraint', 3 indicates 'severe nutrient constraint', 4 indicates 'very severe nutrient constraint', and 5 indicates 'mainly non-soil'25.

level cropping conditions. The explanatory soil statistic used in the model, $S_{c t}$, is the average of $N_{c t}$ and $U_{c t}$.

The weather vector $\mathbf{Z}$ includes weather statistics that summarize the weather conditions over a country's cropland during the growing season. We summarized each weather variable at the country level in year $t$ with a procedure very similar to that used to find the country-level cropland soil statistic $S$. Let $D G S T_{j m t}$ and $N G S T_{j m t}$ indicate the average daytime high and nighttime low temperature in grid cell $j$ in month $m$ of harvest year $t$ (measured in degrees Celsius $)^{8}$. Let $D G S T_{j t}$ and $N G S T_{j t}$ indicate the average of $D G S T_{j m t}$ and $N G S T_{j m t}$, respectively, across grid cell $j$ 's growing season months of harvest year $t$ where we use a grid cell's growing season months for maize to define growing season. Let $P_{j t}$ be the total precipitation in grid cell $j$ during the cell's growing season in harvest year $t$ (measured in millimeters). If a crop was harvested in the spring of year $t$ then some of the weather that contributes to $D G S T_{j t}, N G S T_{j t}$, and $P_{i t}$ occurred in the final months of year $t-1$. Let $D G S T$, $N G S T_{c t}$, and $P_{c t}$ measure the average monthly daytime high, monthly nighttime low, and growing season precipitation, respectively, over $c$ 's cropland during the course of growing season $t$ where weather data is weighted by cropland density in grid cell $j$.

$$
\begin{aligned}
D G S T_{c t} & =\sum_{j \in c} A_{j t} D G S T_{j t} / \sum_{j \in c} A_{j t} \\
N G S T_{c t} & =\sum_{j \in c} A_{j t} N G S T_{j t} / \sum_{j \in c} A_{j t} \\
P_{c t} & =\sum_{j \in c} A_{j t} P_{j t} / \sum_{j \in c} A_{j t}
\end{aligned}
$$

where $A_{j t}$ is the area of grid cell $j$ that was cropped in year $t$. The weather vector $\mathbf{Z}_{\mathrm{ct}}$ in model (1) also includes the squares of $D G S T_{c t}$, $N G S T_{c t}$, and $P_{c t}$.

MATLAB code was used to construct $S_{c t}, D G S T_{c t}, N G S T_{c t}$, and $P_{c t}$. The code and related databases can be found in Supplementary materials under MATLAB Code for creating country-level variables.
Maps of country-level change in agricultural inputs Maps of 1975 - 1977 to 2005 - 2007 country-level changes in various model (1) inputs are given in Supplementary Figure 13Supplementary Figure 21. These figures can be found Supplementary material under the zip file Supplementary Figures.

\section{Data availability}

Dataset 1. "Wide" dataset. doi, 10.5256/f1000research.10419. d146338

\section{ID: UNFAO Country Code}

2. Year

3. Tropical: a 1 indicates that that country is a tropical country and a 0 indicates that the country is a temperate country

4. tons/ha: a country's crop yield in year $t$ in metric tons/ha (I summed all tons of crops produced in a country and divided by total cropped hectares in a country)

5. million kcals/ha: a country's crop yield in year $\mathrm{t}$ in millions of kcals/ha (I summed all kcals of crops produced in a country and divided by total cropped hectares in a country)

6. soilscore: The composite soil quality score of the land that was cropped in year $\mathrm{t}$ in country $\mathrm{k}$ (on a 1 to 5 scale with lower numbers indicating better soil).

7. ha: total cropped hectares in year $t$ in country $\mathrm{k}$

8. rice: percentage of cropped area in rice in year $t$ in country k

9. wheat: percentage of cropped area in wheat in year $t$ in country $\mathrm{k}$

10. sugar: percentage of cropped area in sugarcane in year $t$ in country $\mathrm{k}$

11. grains: percentage of cropped area in coarse grains in year $\mathrm{t}$ in country $\mathrm{k}$ 
12. oil: percentage of cropped area in oil crops in year $t$ in country $\mathrm{k}$

13. fruits: percentage of cropped area in fruits in year $t$ in country k

14. roots: percentage of cropped area in roots and tubers in year $\mathrm{t}$ in country $\mathrm{k}$

15. other: percentage of cropped area in all other crops in year $\mathrm{t}$ in country $\mathrm{k}$

16. davg: The composite average daytime temperature over cropped lands during the growing season year t in country $\mathrm{k}$ (Celsius)

17. navg: The composite average nighttime temperature over cropped lands during the growing season year t in country $\mathrm{k}$ (Celsius)

18. pavg: The total rainfall over cropped lands during the growing season year $\mathrm{t}$ in country $\mathrm{k}(\mathrm{mm})$

19. irr: Fraction of cropped lands that are equipped for irrigation in year $\mathrm{t}$ in country $\mathrm{k}$

20. land: total money invested in agricultural land development divided by cropped hectares in year $\mathrm{t}$ in country $\mathrm{k}$ (2005 constant US \$/ha)

21. eqp: total money invested in agricultural equipment divided by cropped hectares in year $\mathrm{t}$ in country k (2005 constant US \$/ha)

22. fert: kilograms of fertilizer used in the country divided by cropped hectares in year $\mathrm{t}$ in country $\mathrm{k}$.

Dataset 2. "Long" dataset. doi, 10.5256/f1000research.10419. d146339

\section{ID: UNFAO Country Code}

2. Year

3. Tropical: a 1 indicates that that country is a tropical country and a 0 indicates that the country is a temperate country

4. tons/ha: a country's crop yield in year $t$ in metric tons/ha (I summed all tons of crops produced in a country and divided by total cropped hectares in a country)

5. million kcals/ha: a country's crop yield in year $\mathrm{t}$ in millions of kcals/ha (I summed all kcals of crops produced in a country and divided by total cropped hectares in a country)

6. soilscore: The composite soil quality score of the land that was cropped in year $\mathrm{t}$ in country $\mathrm{k}$ (on a 1 to 5 scale with lower numbers indicating better soil).

7. ha: total cropped hectares in year $\mathrm{t}$ in country $\mathrm{k}$

8. rice: percentage of cropped area in rice in year $t$ in country $\mathrm{k}$
9. wheat: percentage of cropped area in wheat in year $t$ in country $\mathrm{k}$

10. sugar: percentage of cropped area in sugarcane in year $t$ in country $\mathrm{k}$

11. grains: percentage of cropped area in coarse grains in year $t$ in country $\mathrm{k}$

12. oil: percentage of cropped area in oil crops in year $t$ in country k

13. fruits: percentage of cropped area in fruits in year $\mathrm{t}$ in country $\mathrm{k}$

14. roots: percentage of cropped area in roots and tubers in year $\mathrm{t}$ in country $\mathrm{k}$

15. other: percentage of cropped area in all other crops in year $\mathrm{t}$ in country $\mathrm{k}$

16. davg: The composite average daytime temperature over cropped lands during the growing season year t in country $\mathrm{k}$ (Celsius)

17. navg: The composite average nighttime temperature over cropped lands during the growing season year t in country $\mathrm{k}$ (Celsius)

18. pavg: The total rainfall over cropped lands during the growing season year $\mathrm{t}$ in country $\mathrm{k}(\mathrm{mm})$

19. irr: Fraction of cropped lands that are equipped for irrigation in year $\mathrm{t}$ in country $\mathrm{k}$

20. land: total money invested in agricultural land development divided by cropped hectares in year $\mathrm{t}$ in country k (2005 constant US \$/ha)

21. eqp: total money invested in agricultural equipment divided by cropped hectares in year $\mathrm{t}$ in country k (2005 constant US \$/ha)

Dataset 3. Accuracy of decision trees. doi, 10.5256/ f1000research.10419.d146340 ${ }^{10}$

\section{Author contributions}

E.J.N. did everything other than construct the decision trees. C.B.C constructed the decision trees. C.B.C. also wrote and edited portions of the text.

\section{Competing interests}

No competing interests were disclosed.

Grant information

The author(s) declared that no grants were involved in supporting this work.

\section{Acknowledegments}

The authors wish to thank Jae Bradley, Clarissa Hunnewell, and Isabel Schwartz, undergraduates at Bowdoin College, for help with putting datasets together and analyzing data. 


\section{Supplementary materials} Supplementary Figures 1-21:

Click here to access the data.

(1) Decision tree for globe, yield measured in $\mathrm{Mg} \mathrm{ha}^{-1}$, using the "long" dataset.

(2) Decision tree for temperate region, yield measured in $\mathrm{Mg} \mathrm{ha}^{-1}$, using the "long" dataset.

(3) Decision tree for tropics, yield measured in $\mathrm{Mg} \mathrm{ha}^{-1}$, using the "long" dataset.

(4) Decision tree for globe, yield measured in $\mathrm{M} \mathrm{kcals} \mathrm{ha}^{-1}$, using the "long" dataset.

(5) Decision tree for temperate region, yield measured in $\mathrm{M} \mathrm{kcals} \mathrm{ha}^{-1}$, using the "long" dataset.

(6) Decision tree for tropics, yield measured in $\mathrm{M} \mathrm{kcals} \mathrm{ha}^{-1}$, using the "long" dataset.

(7) Decision tree for globe, yield measured in $\mathrm{Mg} \mathrm{ha}^{-1}$, using the "wide" dataset.

(8) Decision tree for temperate region, yield measured in $\mathrm{Mg} \mathrm{ha}^{-1}$, using the "wide" dataset.

(9) Decision tree for tropics, yield measured in $\mathrm{Mg} \mathrm{ha}^{-1}$, using the "wide" dataset.

(10) Decision tree for globe, yield measured in $\mathrm{M} \mathrm{kcals} \mathrm{ha}^{-1}$, using the "wide" dataset.

(11) Decision tree for temperate region, yield measured in $\mathrm{M} \mathrm{kcals} \mathrm{ha}^{-1}$, using the "wide" dataset.

(12) Decision tree for tropics, yield measured in $\mathrm{M} \mathrm{kcals} \mathrm{ha}^{-1}$, using the "wide" dataset.

(13) Percentage change in 1975-1977 to 2005-2007 growing season daytime temperature by country.

(14) Percentage change in 1975-1977 to 2005-2007 growing season nighttime temperature by country.

(15) Percentage change in 1975-1977 to 2005-2007 growing season precipitation by country.

(16) Percentage change in 1975-1977 to 2005-2007 soil score by country.

(17) Percentage change in 1975-1977 to 2005-2007 hectares of irrigation capacity per cropped hectare by country.

(18) Percentage change in 1975-1977 to 2005-2007 equipment investment (\$2005) per cropped hectare by country.

(19) Percentage change in 1975-1977 to 2005-2007 land investment (\$2005) per cropped hectare by country.

(20) Percentage change in 1975-1977 to 2005-2007 all crop M kcals per hectare yield by country.

(21) Percentage change in 1975-1977 to 2005-2007 all crop Mg per hectare yield by country.

Supplementary Table 1: Econometric estimates of fixed effects model (1) with the "long" global, tropics, and temperate datasets. Estimated coefficients with standard errors in parentheses. Standard errors are robust standard errors. '***' indicates statistical significance at $p=0.01$, ' $* *$ ' indicates statistical significance at $p=0.05$, and ' $*$ ' indicates statistical significance at $p=0.10$. Country fixed effect coefficients and SE are available upon request.

Click here to access the data.

Supplementary Table 2: Econometric estimates of fixed effects model (1) with the "wide" global, tropics, and temperate datasets. Click here to access the data.

Supplementary Methods: Crop groups used to define crop mix.

Click here to access the data.

MATLAB Code for Tables 1 and 2.

Click here to access the data.

MATLAB Code for creating country-level variables.

Click here to access the data.

Stata Files.

Click here to access the data. 
1. Schlenker W, Haneman WM, Fisher AC: The impact of global warming on U.S. agriculture: an econometric analysis of optimal growing conditions. Rev Econ Stat. 2006; 88(1): 113-125.

Publisher Full Text

2. Schlenker W, Roberts MJ: Nonlinear temperature effects indicate severe damages to U.S. crop yields under climate change. Proc Natl Acad Sci U S A. 2009; 106(37): 15594-15598.

PubMed Abstract | Publisher Full Text | Free Full Text

3. Ashenfelter $\mathrm{O}$, Storchmann $\mathrm{K}$ : Using hedonic models of solar radiation and weather to assess the economic effect of climate change: the case of Mose valley vineyards. Rev Econ Stat. 2010; 92(2): 333-349.

Publisher Full Text

4. Lobell DB, Schlenker W, Costa-Roberts J: Climate trends and global crop production since 1980. Science. 2011; 333(6042): 616-620.

PubMed Abstract | Publisher Full Text

5. Tilman D, Balzer C, Hill J, et al:: Global food demand and the sustainable intensification of agriculture. Proc Natl Acad Sci U S A. 2011; 108(50): 20260-20264

PubMed Abstract | Publisher Full Text | Free Full Text

6. Foley JA, Ramankutty N, Brauman KA, et al:: Solutions for a cultivated planet Nature. 2011; 478(7369): 337-342. PubMed Abstract | Publisher Full Text

7. Beddow JM, Pardey PG: Moving matters: the effect of location on crop production. J Econ Hist. 2015; 75(1): 219-249. Publisher Full Text

8. Nelson E, Congdon CB: Dataset 1 in: Measuring the relative importance of different agricultural inputs to global and regional crop yield growth since 1975. F1000Research. 2016a. Data Source

9. Nelson E, Congdon CB: Dataset 2 in: Measuring the relative importance of different agricultural inputs to global and regional crop yield growth since 1975. F1000Research. 2016b. Data Source

10. Nelson E, Congdon CB: Dataset 3 in: Measuring the relative importance of different agricultural inputs to global and regional crop yield growth since 1975. F1000Research. 2016c. Data Source

11. FAOSTAT (Food and Agriculture Organization of the United Nations): FAOStat database. 2011. Reference Source

12. Alston JM, Pardey PG: Agriculture in the global economy. J Econ Perspect. 2014; 28(1): 121-146.

Publisher Full Text

13. Anderson K: Globalization's effects on world agricultural trade, 1960-2050. Philos Trans R Soc Lond B Biol Sci. 2010; 365(1554): 3007-3021. PubMed Abstract | Publisher Full Text | Free Full Text

14. Vera-Diaz MD, Kaufmann RK, Nepstad DC, et al:: An interdisciplinary mode of soybean yield in the Amazon Basin: the climatic, edaphic, and economic determinants. Ecol Econ. 2008; 65(2): 420-431.

Publisher Full Text

15. Lobell DB, Cassman KG, Field CB: Crop yield gaps: their importance, magnitudes, and causes. Annu Rev Environ Resour. 2009; 34(1): 179-204. Publisher Full Text

16. Costinot A, Donaldson D: Ricardo's theory of comparative advantage: old idea, new evidence. Am Econ Rev. (National Bureau of Economic Research, No. w17969), 2012; 102(3): 453-58.

Publisher Full Text

17. Pollack SL: Consumer demand for fruit and vegetables: the U.S. example.
Changing Structure of Global Food Consumption and Trade. 2001; 6: 49-54. Reference Source

18. Pingali P: Westernization of Asian diets and the transformation of food systems: implications for research and policy. Food Policy. 2007; 32(3): 281-298. Publisher Full Text

19. Regmi A, Gehlhar M: New Directions in Global Food Markets. AlB-794. USDA ERS. 2005

Reference Source

20. Schnepf RD, Dohlman E, Bolling C: Agriculture in Brazil and Argentina: Developments and Prospects for Major Field Crops. Market and Trade Economics Division, Economic Research Service, U.S. Department of Agriculture, Agriculture and Trade Report, WRS-01-03. 2001. Reference Source

21. Peng S, Huang J, Sheehy JE, et al:: Rice yields decline with higher night temperature from global warming. Proc Natl Acad Sci U S A. 2004; 101(27): 9971-9975. PubMed Abstract | Publisher Full Text | Free Full Text

22. Fulu $\mathrm{T}$, Yokozawa $\mathrm{M}, \mathrm{Xu} \mathrm{Y}$, et al.: Climate changes and trends in phenology and yields of field crops in China, 1981-2000. Agr Forest Meteorol. 2006; 138(1-4): 82-92.

Publisher Full Text

23. Thomison P: Can warm nights reduce grain yield in corn? C.O.R.N. NewsletterOhio State University. 2010; 22. Reference Source

24. Anderegg WR, Ballantyne AP, Smith WK, et al.: Tropical nighttime warming as a dominant driver of variability in the terrestrial carbon sink. Proc Natl Acad SCi U S A. 2015; 112(51): 15591-15596. PubMed Abstract | Publisher Full Text | Free Full Text

25. Fischer G, Nachtergaele F, Prieler S, et al:: Global Agro-ecological Zones Assessment for Agriculture (GAEZ 2008). IIASA, Laxenburg, Austria and FAO, Rome, Italy; 2008

26. West PC, Gibbs HK, Monfreda C, et al.: Trading carbon for food: global comparison of carbon stocks vs. crop yields on agricultural land. Proc Nat Acad Sci U S A. 2010; 107(46): 19645-19648. PubMed Abstract | Publisher Full Text | Free Full Text

27. Laurance WF, Sayer J, Cassman KG: Agricultural expansion and its impacts on tropical nature. Trends Ecol Evol. 2014; 29(2): 107-116.

PubMed Abstract | Publisher Full Text

28. Quinlan JR: C4.5: Programs for machine learning. Morgan Kaufmann, Publishers 1993.

Reference Source

29. Loh WY: Classification and regression trees. In: Wiley Interdisciplinary Reviews: Data Mining and Knowledge Discovery. 2011; 1(1): 14-23. Publisher Full Text

30. Varian HR: Big data: New tricks for econometrics. J Econ Perspect. 2014; 28(2): 3-27. Publisher Full Text

31. Tai AP, Martin MV, Heald CL: Threat to future global food security from climate change and ozone air pollution. Nat Clim Chang. 2014; 4: 817-821. Publisher Full Text

32. Mauser W, Klepper G, Zabel F, et al.: Global biomass production potentials exceed expected future demand without the need for cropland expansion. Nat Commun. 2015; 6: 8946.

PubMed Abstract | Publisher Full Text | Free Full Text

33. Balmford A, Green R, Phalan B: What conservationists need to know about farming. Proc Biol Sci. 2012; 279(1739): 2714-2724. PubMed Abstract | Publisher Full Text | Free Full Tex

34. Ramankutty N, Foley J: Estimating historical changes in global land cover: croplands from 1700 to 1992. Global Biogeochem Cy. 1999; 13: 997-1028. Publisher Full Text 


\title{
Open Peer Review
}

\section{Current Peer Review Status: ? ?}

\section{Version 1}

Reviewer Report 28 February 2017

https://doi.org/10.5256/f1000research.11227.r20596

(c) 2017 Mueller N. This is an open access peer review report distributed under the terms of the Creative Commons Attribution License, which permits unrestricted use, distribution, and reproduction in any medium, provided the original work is properly cited.

\author{
Nathaniel D Mueller \\ Department of Earth and Planetary Sciences, Harvard University, Cambridge, MA, 02138, USA
}

Nelson and Congdon provide an analysis of historical crop yield evolution across the globe. The analysis is conceptually straightforward and provides a useful, high-level perspective. Overall, I think the analysis is a useful contribution to the literature on global crop production trends.

One of the strengths of the analysis is the fact that the authors focus on production across many crops, which allows the authors to talk about macro-level trends. However, this lumping together of many crops leads their findings to be heavily dependent upon crop mix trends. This is partly alleviated by putting crops on a 'common currency' using kcals. However, I would like to see more discussion about crop weight, water content of harvested products, and calorie content of various crops and how these characteristics drive some of the results. I am thinking specifically how sugarcane and roots and tubers fall out as very important in the decision-tree analysis.

I find the current format of the paper somewhat disorienting. Although the Results section contains information about the analytical methods, data sources are not described in much detail, nor are they very well-described in the "Dataset" boxes later on Page 4. And why should the analytical methods sections be contained within the Results? The Materials and Methods section at the end provides extensive documentation of the equations and statistical approach, but still little information about the data. Nowhere did I see the source of climate data described, the growing season definitions, the soils dataset, kcal conversions, etc ... these are essential details to evaluate the quality of the research. The authors will have to decide what re-organization makes sense in the context of F1000 formatting guidelines, but the current orientation and missing details makes the manuscript hard to read front-to-back.

The authors should be more explicit that they are mixing together variables that directly influence plant growth (e.g. weather, nutrient availability, and fertilizers) and those that proxy for unobserved factors that may influence plant growth (e.g. time and machinery investment).

I take issue with the authors' statement on Page 13: "Several suggested paths to greater food production are not supported by our analysis. Cropland extensification contributed little to yield 
gains in the immediate past and are not likely to do so in the future." This statement about cropland extensification is true, but cropland extensification doesn't need to boost yields to increase food production ... more food production is simply achieved due to greater harvested area. Extensification has many negative environmental impacts, which could be discussed.

The "Low" and "High" columns in the Table 1 legend and elsewhere are poorly described. You only have one yield observation per country and year, so how are you using an interquartile range of yields? What information should the reader be getting here? It would be most interesting to present a confidence interval on the size of the area between the expected yield curve and the counterfactual's yield curve, through utilizing your distribution of coefficient estimates from the bootstrap. Based on what I think is the relevant Methods text on Page 15, it seems like the authors have done something slightly different. It's unclear what information we are supposed to be gleaning from their calculation, and there is no consistent directionality to the Low vs High estimates (nor do they usually bracket the mean value). I suggest the authors use their distribution of coefficient estimates to provide a straightforward-to-interpret confidence interval on the counterfactual area calculation itself. Calculate the counterfactual area for each combination of coefficients across all countries, then report percentiles of that counterfactual area distribution.

I agree with the previous reviewer that attempting to use both daytime and nighttime temperatures is likely pushing the data too hard. The strange coefficient estimates certainly seem to imply that to be the case.

Page 2, Introduction, paragraph 1: References 1-3 do not support the statement in the first sentence, as they do not actually analyze the impacts of historical climate trends on historical crop yields. Reference 4 does support the statement.

Page 2, Introduction, paragraph 2: If you introduce the term "cropped footprint" here it needs to be differentiated from "land".

Page 3: It might be easier for readers to call the two versions of the analysis "with fertilizer" and "without fertilizer" instead of "wide" and "long".

Page 4: The time trend also captures the diffusion of modern crop varieties (see, for example, Evenson and Gollin $2003^{1}$ ).

Page 12: It seems appropriate to reiterate the very high productivity (and weight) of sugarcane, root and tuber crops here, given their strong predictive power in the decision tree analysis.

\section{References}

1. Evenson RE, Gollin D: Assessing the impact of the green revolution, 1960 to 2000.Science. 2003; 300 (5620): 758-62 PubMed Abstract | Publisher Full Text

Competing Interests: No competing interests were disclosed.

I confirm that I have read this submission and believe that I have an appropriate level of 


\section{expertise to confirm that it is of an acceptable scientific standard, however I have significant reservations, as outlined above.}

Reviewer Report 08 February 2017

https://doi.org/10.5256/f1000research.11227.r19369

(C) 2017 Thomas T. This is an open access peer review report distributed under the terms of the Creative Commons Attribution License, which permits unrestricted use, distribution, and reproduction in any medium, provided the original work is properly cited.

\section{Timothy S Thomas}

Environment and Production Technology Division, International Food Policy Research Institute (IFPRI), Washington, DC, USA

I found the article by Nelson and Congdon to be quite interesting in what they attempt to do, how they approach the problem, and in the results that they get. Essentially, aggregating FAO production figures for each country from 1975 to the mid-2000s, they run fixed effects regressions to determine the source of productivity growth in agriculture, accounting for weather. One of the most interesting innovations that they did was to separate analyses for temperate and tropical countries. They find that most growth in temperate countries is due to growth in agricultural technology, along with growth in inputs other than land, fertilizer, irrigation, and farm equipment (e.g., pesticides). However, they actually find that the growth rate from agricultural technology and inputs excluding the ones mentioned is negative.

\section{Critique of One of Their Main Findings}

The fact that there is a difference between temperate and tropical countries is quite interesting and entirely believable, but the fact that for tropical countries the growth from technology and other inputs is negative seems implausible. While publishing such a result would not be improper, it would seem important for the authors to suggest a stronger explanation as to why it might be feasible.

Even from within the data, they could do more to understand the result. For example, if they differentiated between Asia, Africa, and Latin America, could they find whether some have negative growth rates while others have positive growth rates? I have a difficult time thinking of a scenario where this could be true for Asia with the Green Revolution, but could understand where this might be true for Africa, especially with the transition post-independence and the decline of many agriculture-supporting institutions.

Furthermore, they could try to differentiate by time. Is there a different trend before and after the mid-1980's? They could either do this by dividing the dataset into two groups, or could use a quadratic term for the time variable. Answering the region and time questions could shed much light on the source of the negative technological growth rates in the tropics.

\section{Statistical Analysis Issues}


I endeavored to reproduce their results in Stata, but was unsuccessful. I tried both reg (with and without country dummies) and xtreg, with and without weights and using different variance matrix specifications. They did not say in their article whether they use weights in their regressions, but it would seem that weighting by harvested area (or some similar variable) would allow for better conclusions to be drawn for the aggregations used in their article.

It seemed improper to use total harvested area as an explanatory variable and then interpret the variable as the authors do. That is, large values of harvested area can be thought of as having two components: either high percentage of national land in agriculture; a large country; or both. The authors, however, treat that variable as if it were cropland expansion, which it is not. They should possibly use the proportional change in harvested area from previous year, or possibly the proportion of cropland in total land for the country.

In their regressions, the authors include daytime and nighttime temperatures, along with their squares. Unfortunately, the signs they get in their regressions are implausible considering where the inflection points are. For example, they find that yields rise rapidly in the tropics above 8 degrees $C$ during the daytime. While they will rise above 8 degrees $C$, their regressions suggest that yield continue to rise even above 40 degrees $C$. The problem is that daytime and nighttime temperatures are very highly correlated, and that it is very difficult to estimate them both in the same regression. Regressions will clearly signal joint significance, but rarely will there be individual significance, and the signs on the parameters are often implausible. The authors should probably elect to focus on just daytime temperatures, so that they can contribute to evaluating the impact of climate change on agricultural productivity.

One additional issue related to data: I was unable to find in their article what the source of their climate data was, and it would be important to include that. The same is true for the soil score.

\section{Interpretation Issues}

The authors endeavor to explain why countries changed their proportions of crops grown, without actually looking at the data to see if they did change. They know the global, temperate, and tropical aggregates changed, but these could have come about without a single country changing proportions, but rather by countries changing their harvested areas. That is, if the countries with the largest harvested areas in 1975 were different than the countries with large harvest areas in the mid-2000's, and if the large countries in 1975 had vastly different distributions than those in the mid-2000's, then the aggregate ratios would change without a single country changing their proportions. I'm not suggesting that the authors are wrong about the proportions changing within countries, but it would be helpful to give an example (perhaps India or China), or some kind of table that shows how grains or some other crop group has changed through time, by country.

It is important to point out that the regressions are not entirely proper the way the authors did them. All of the input variables are endogenous, and they did not attempt to use instrumental variables to control for the endogeneity, so the parameters are biased. This may be acceptable for analyzing historical data for the sake of determining the influence of various variables on yields much like a hedonic regression - but it is not proper for making policy recommendations for the future. So when the authors make conclusions from estimates based on the endogenous variables (e.g., they suggested that the tropics should reduce grain production and increase fruit and 
sugarcane production to maximize global calories and yields), one wonders whether they have gone too far in drawing implications from an improperly specified model. The proportions of each crop group in historical data were chosen by individual agents maximizing their utility, taking into consideration market prices along with knowledge of the climate and soils. Implementing policy to change these proportions in order to maximize yields and calories is likely to backfire.

\section{Recommendation}

The article clearly makes an important contribution to understanding sources of yield growth globally. There are some relatively minor issues addressed in the preceding sections which can be dealt with, making the article much better for publication.

Competing Interests: No competing interests were disclosed.

I confirm that I have read this submission and believe that I have an appropriate level of expertise to confirm that it is of an acceptable scientific standard, however I have significant reservations, as outlined above.

The benefits of publishing with F1000Research:

- Your article is published within days, with no editorial bias

- You can publish traditional articles, null/negative results, case reports, data notes and more

- The peer review process is transparent and collaborative

- Your article is indexed in PubMed after passing peer review

- Dedicated customer support at every stage

For pre-submission enquiries, contact research@f1000.com 